\title{
The role of hydrophobic interactions in positioning of peripheral proteins in membranes
}

\author{
Andrei L Lomize*1, Irina D Pogozheva ${ }^{1}$, Mikhail A Lomize ${ }^{2}$ and \\ Henry I Mosberg 1
}

Address: ${ }^{1}$ Department of Medicinal Chemistry, College of Pharmacy, University of Michigan, Ann Arbor, MI 48109-1065, USA and ${ }^{2}$ College of Literature, Science and the Arts, University of Michigan, Ann Arbor, MI 48109-1065, USA

Email: Andrei L Lomize* - almz@umich.edu ; Irina D Pogozheva - irinap@umich.edu; Mikhail A Lomize - mlomize@umich.edu; Henry I Mosberg - him@umich.edu

* Corresponding author

Published: 29 June 2007

BMC Structural Biology 2007, 7:44 doi:10.1 186/1472-6807-7-44
Received: 13 March 2007

Accepted: 29 June 2007

This article is available from: http://www.biomedcentral.com/1472-6807/7/44

(C) 2007 Lomize et al; licensee BioMed Central Ltd.

This is an Open Access article distributed under the terms of the Creative Commons Attribution License (http://creativecommons.org/licenses/by/2.0), which permits unrestricted use, distribution, and reproduction in any medium, provided the original work is properly cited.

\begin{abstract}
Background: Three-dimensional (3D) structures of numerous peripheral membrane proteins have been determined. Biological activity, stability, and conformations of these proteins depend on their spatial positions with respect to the lipid bilayer. However, these positions are usually undetermined.
\end{abstract}

Results: We report the first large-scale computational study of monotopic/peripheral proteins with known 3D structures. The optimal translational and rotational positions of 476 proteins are determined by minimizing energy of protein transfer from water to the lipid bilayer, which is approximated by a hydrocarbon slab with a decadiene-like polarity and interfacial regions characterized by water-permeation profiles. Predicted membrane-binding sites, protein tilt angles and membrane penetration depths are consistent with spin-labeling, chemical modification, fluorescence, NMR, mutagenesis, and other experimental studies of 53 peripheral proteins and peptides. Experimental membrane binding affinities of peripheral proteins were reproduced in cases that did not involve a helix-coil transition, specific binding of lipids, or a predominantly electrostatic association. Coordinates of all examined peripheral proteins and peptides with the calculated hydrophobic membrane boundaries, subcellular localization, topology, structural classification, and experimental references are available through the Orientations of Proteins in Membranes (OPM) database.

Conclusion: Positions of diverse peripheral proteins and peptides in the lipid bilayer can be accurately predicted using their 3D structures that represent a proper membrane-bound conformation and oligomeric state, and have membrane binding elements present. The success of the implicit solvation model suggests that hydrophobic interactions are usually sufficient to determine the spatial position of a protein in the membrane, even when electrostatic interactions or specific binding of lipids are substantial. Our results demonstrate that most peripheral proteins not only interact with the membrane surface, but penetrate through the interfacial region and reach the hydrocarbon interior, which is consistent with published experimental studies. 


\section{Background}

More than half of all proteins interact with membranes. These proteins can be classified as transmembrane, integral monotopic, or peripheral. Transmembrane proteins comprise numerous receptors, channels, transporters, photosystems, and respiratory complexes. Integral monotopic proteins associate with the membrane permanently, but do not traverse the lipid bilayer. Peripheral proteins are water-soluble and associate with lipid bilayers reversibly. They include numerous membrane-associated enzymes, transporters, signaling lipid-binding domains (C1, C2, PH, FYVE, PX, ENTH, ANTH, FERM, etc.), antibacterial peptides, hormones, toxins, pulmonary surfactant-associated polypeptides, peptaibols, lipopeptides, etc. [2-4]. Experimental three-dimensional (3D) structures are currently available for hundreds of membrane-associated proteins; however, their precise spatial positions in the lipid bilayer are usually unknown. The arrangement of proteins in membranes may affect their conformation, biological activity, folding, thermodynamic stability, and binding of surrounding macromolecules and substrates $[2,5]$.

Spatial positions in the lipid bilayer have been experimentally studied for approximately 50 peripheral proteins with known three-dimensional (3D) structures using sitedirected spin labeling, chemical labeling, measurement of membrane binding affinities of protein mutants, fluorescence spectroscopy, solution or solid-state NMR spectroscopy, ATR FTIR spectroscopy, or X-ray diffraction. In many cases, some of the membrane-embedded residues have been identified (Tables 1). Membrane-docking geometries of four $\mathrm{C} 2$ domains, monomeric EEA1 FYVE domain, and secreted phospholipase A2 have been defined from spin-labeling or other experimental data [610], although the coordinates of the proteins with lipid bilayer boundaries are publicly available only for the human pancreatic phospholipase A2 [11].

Positions of proteins in membranes can also be determined computationally. Three major categories of computational methods can be used for this purpose: molecular dynamics simulations with explicit lipids $[12,13]$, energy minimization of the protein in the hydrophobic slab using the implicit solvation model [14-16], or optimization of electrostatic interaction energy between cationic proteins and a negatively charged planar membrane surface [17-22]. Most computational studies have been conducted for $\alpha$-helical peptides and transmembrane proteins. Spatial positions with respect to the membrane have been theoretically predicted and compared with experimental data only for a few proteins, such as toxins, membrane-targeting domains, viral matrix domains, phospholipases $\mathrm{A} 2$, and prostaglandine synthase $([13,16,19-22]$. However, the coordinates of these proteins with their membrane boundaries are not available. Thus, it is difficult to compare the reliability and precision of different methods.

We report here the first large-scale computational analysis of peripheral proteins from the Protein Data Bank (PDB) [23]. Several hundreds of peripheral proteins and peptides were considered. Their spatial positions in the membrane were calculated, compared with available experimental data, and deposited in our OPM database [24]. The computational approach applied implements the commonly accepted model of the lipid bilayer in a fluid state, where the hydrocarbon core region formed by lipid acyl chains is surrounded by two interfacial regions formed by lipid head groups. The hydrocarbon region has well defined boundaries where the effective concentration of water changes from nearly zero to $\sim 2 \mathrm{M}$ at a distance of several angstroms [25]. The optimal rotational and translational position of each protein with respect to the lipid bilayer is determined by minimizing transfer energy of the protein from water to the membrane hydrocarbon core approximated by a nonpolar solvent decadiene. In this approximation, the binding of a protein to the membrane is driven by hydrophobic interactions and opposed by desolvation of polar and charged groups. This approach has been successfully tested for integral transmembrane proteins [26]. It has no training or adjustable parameters that must be optimized specifically for the proteins studied in the present work. All required atomic solvation parameters were previously determined from experimental water-decadiene transfer energies of model organic compounds [27].

Comparison with experimental studies demonstrated that the implicit solvent model performs well for 53 experimentally studied peripheral proteins and peptides with diverse $3 \mathrm{D}$ structures. Hence, this model was applied to several hundreds of other proteins whose spatial positions in membranes have not yet been experimentally evaluated. This analysis allows estimation of the contributions of hydrophobic interactions to membrane binding energies and identification of membrane-anchoring motifs of individual proteins, such as exposed non-polar loops, amphiphilic $\alpha$-helices, $\beta$-hairpins, or non-covalently bound lipids.

\section{Results}

\section{Comparison with experimental studies of protein positions in membranes}

To verify the method, we selected a diverse set of 53 peripheral proteins with known 3D structures, whose spatial positions in the membrane have been experimentally studied (Tables 1 and 2, Figures 1, 2, 3, 4, 5, 6, 7; see selection criteria in the Methods). Table 1 includes cases in which individual membrane-bound residues have been 
Table I: Comparison of membrane-bound residues in peripheral proteins according to experimental studies and calculations peripheral proteins.

\begin{tabular}{|c|c|c|c|c|c|c|c|}
\hline \multirow[b]{2}{*}{ Protein name } & \multirow[b]{2}{*}{ PDB id } & \multicolumn{3}{|c|}{ Experiment $^{\mathrm{a}}$} & \multicolumn{3}{|c|}{ Calculationb } \\
\hline & & $\begin{array}{l}\text { Residues buried from } \\
\text { water or important } \\
\text { for membrane } \\
\text { binding }\end{array}$ & Method & References & $\begin{array}{l}\Delta G_{\text {calc }} \\
(\mathbf{k c a l} / \mathrm{mol})\end{array}$ & $D(\AA)$ & $\begin{array}{l}\text { Residues penetrating } \\
\text { the hydrocarbon } \\
\text { membrane core }\end{array}$ \\
\hline \multicolumn{8}{|c|}{ Lipid clamps (specific binding of lipid ligands) } \\
\hline C2 domain of phospholipase $A 2$ & $\underline{|r| w}$ & $\begin{array}{l}\text { A34, F35, G36, M38, } \\
\text { L39, Y96, V97, M98 }\end{array}$ & $\mathrm{Bn}, \mathrm{SL}$ & {$[6,84,85]$} & -7.1 & 5.3 & $\begin{array}{l}\text { A34, F35, G36, M38, } \\
\text { L39, Y96, V97, M98 }\end{array}$ \\
\hline C2A domain of synaptotagmin I & Ibyn & MI73, GI74, F234 & $\mathrm{Bn}, \mathrm{SL}$ & {$[7,86]$} & -4.4 & 3.7 & MI73, GI74, F234 \\
\hline $\mathrm{C} 2$ domain of protein knase $\mathrm{C} \alpha$ & Idsy & N189, R249, R252 & SL & {$[8]$} & -2.0 & 1.5 & $\mathrm{P} I 88, \mathbf{N} 189, \mathrm{~T} 250$ \\
\hline C2B domain of synaptotagmin I & luov & G305, 1367 & SL & [9] & -4.3 & 2.4 & $\begin{array}{l}\text { V304, G305, 1367, } \\
\text { G368 }\end{array}$ \\
\hline $\mathrm{C} 2$ domain of protein kinase $\mathrm{C} \varepsilon$ & Igmi & 189, Y91 & $\mathrm{Bn}$ & [87] & -5.1 & 2.4 & V29, P3I, 189 \\
\hline PX domain (p40phox) & $\mathrm{ln} 6 \mathrm{~h}$ & $F 35$, Y94, V95 & $\mathrm{Bn}$ & [39] & -4.5 & 3.2 & F35, Y94, V95 \\
\hline PX domain (p47phox) & $\underline{107 \mathrm{k}}$ & W80 & $\mathrm{Bn}$ & [39] & -1.9 & 1.4 & W80 \\
\hline FYVE domain of EEAI & Ihyi & V2I, T22 & NMR & {$[40]$} & -2.9 & 2.5 & V2I, T22 \\
\hline FYVE domain of $V_{p s 27 p}$ & Ivfy & LI 85, LI 86 & $\mathrm{Bn}$ & {$[88]$} & -4.0 & 2.9 & LI85, LI86 \\
\hline $\mathrm{Cl}$ domain of protein kinase $\mathrm{C} \delta$ & $\overline{\mathrm{Iptr}}$ & W252, L254, V255 & $\mathrm{Bn}$ & [89] & -5.7 & 6.8 & $\begin{array}{l}\text { M239, P24I, L250, } \\
\text { W252, G253, L254, } \\
\text { V255 }\end{array}$ \\
\hline Epsin ENTH domain & $\underline{\text { IhOa }}$ & L6, MIO & $\mathrm{Bn}$ & {$[77]$} & -5.2 & 2.9 & L6, MIO, II3, VI4 \\
\hline Discoidin domain of factor $V$ & $\overline{I \mathrm{CZs}}$ & W26, W27 & $\mathrm{Bn}$ & [90] & -3.0 & 4.2 & $\begin{array}{l}\text { W26, W27, L79, and } \\
\text { S80 }\end{array}$ \\
\hline Discoidin domain of factor $\mathrm{Va}$ & Isdd & $\begin{array}{l}\text { Y1956, LI957, } \\
\text { W2063, W2064 }\end{array}$ & $\mathrm{Bn}$ & {$[91]$} & -5.6 & 3.3 & $\begin{array}{l}\text { Y1956, L1957, } \\
\text { W2063, W2064 }\end{array}$ \\
\hline Discoidin domain of factor VIII & $\underline{I d 7 p}$ & $\begin{array}{l}\text { M2199, F2200, } \\
\text { L225 I, L2252 }\end{array}$ & $\mathrm{Bn}$ & {$[92]$} & -8.1 & 3.9 & $\begin{array}{l}\text { M2199, F2200, } \\
\text { L225 I, L2252 }\end{array}$ \\
\hline Annexin V & $\underline{\operatorname{la} 8 \mathrm{a}}$ & $\begin{array}{l}\text { T72, } \underline{S 144}, W 185 \\
\underline{S 228}, \underline{S 303}\end{array}$ & SL & [93] & -6.3 & 2.5 & $\begin{array}{l}\text { L29, T72, AI0I, } \\
\text { WI } 85, \text { A } 260\end{array}$ \\
\hline Annexin XII & $\underline{\mathrm{Idm} 5}$ & $\underline{\mathrm{E}} 42, \underline{\mathrm{S} \mid 44}, \underline{\mathrm{G} \mid 45}$ & SL & {$[94]$} & -8.3 & 3.1 & 129, LI0I, II85 \\
\hline Equinatoxin II & $\underline{\text { Iaz }}$ & $\overline{W 112}$ & NMR & [95] & -2.2 & 3.1 & P8I, V82, WII 2 \\
\hline
\end{tabular}

Other proteins

\begin{tabular}{|c|c|c|c|c|c|c|c|}
\hline Prostaglandin $\mathrm{H} 2$ synthase $\mathrm{I}$ & $\underline{1 q 4 g}$ & $\begin{array}{l}\text { I74, W75, W77, L78, } \\
\text { F88, F91, L92, W98, } \\
\text { L99, FIO2 }\end{array}$ & $\mathrm{Bn}, \mathrm{Fn}$ & [96] & -37.8 & 7.2 & $\begin{array}{l}\text { I74, W75, W77, L78, } \\
\text { T8I, L82, F88, F9I, } \\
\text { L92, W98, L99, FI02, } \\
\text { VI03, TI06, FI07, II } 08\end{array}$ \\
\hline Antimicrobial peptide kalata BI & $\underline{|n b|}$ & W19-V2I, L27-V29 & NMR & [97] & -5.4 & 5.2 & W19-V2I, L27-V29 \\
\hline $\begin{array}{l}\text { Pancreatic phospholipase } A_{2} \text {, } \\
\text { group IB }\end{array}$ & $4 p 2 p$ & W3 & $\mathrm{Flq}$ & {$[11]$} & -8.7 & 3.5 & $\begin{array}{l}\text { W3, HI7, LI9, M20, } \\
\text { L64, V65 }\end{array}$ \\
\hline Bee venom phospholipase $A_{2}$ & $\underline{1 p o c}$ & $12, \underline{\mathrm{K} I 4}, 178$ & $\mathrm{SL*}$ & {$[42]$} & -10.3 & 5.7 & $\begin{array}{l}\text { II, 12, Y3, P4, G5,178, } \\
\text { F82, M86, L90 }\end{array}$ \\
\hline $\begin{array}{l}\text { Human secretory phospholipase } \\
\mathrm{A}_{2} \text {, group Ila }\end{array}$ & $\underline{\ln 28}$ & $\begin{array}{l}\text { V3, K10, LI9, F23, } \\
\text { F63 }\end{array}$ & SL* & {$[43]$} & -6.6 & 4.8 & V3, L19, F23, F63 \\
\hline $\begin{array}{l}\text { Snake venom phospholipase } A_{2} \text {, } \\
\text { group I }\end{array}$ & Ipoa & W6I, F64, YII0 & $\mathrm{Bn}$ & [98] & -5.4 & 4.5 & $\begin{array}{l}\text { Y3, WI8, W19, W6I, } \\
\text { F64 }\end{array}$ \\
\hline $\begin{array}{l}\text { Snake venom phospholipase } A_{2} \text {, } \\
\text { group II }\end{array}$ & Ivap & W20, W30, W109 & $\mathrm{FL}$ & [99] & -10.2 & 4.3 & $\begin{array}{l}\text { F3, MI3, LI9, W30, } \\
\text { M6I, W109 }\end{array}$ \\
\hline $\begin{array}{l}\text { Snake venom phospholipase } A_{2} \text {, } \\
\text { group IIB }\end{array}$ & $\underline{\text { ljia }}$ & $\underline{Y \mid 20}, P I 2 I, I \mid 24, \underline{L I 25}$ & $\mathrm{Bn}$ & {$[100]^{\mathrm{d}}$} & -8.7 & 3.1 & $\begin{array}{l}\text { V20, F24, Al|9, PI2I, } \\
\text { II } 24\end{array}$ \\
\hline Phospholipase C & 2ptd & 143, W47, W242 & $\mathrm{Bn}$ & {$[101]$} & -6.0 & 3.9 & $\begin{array}{l}\text { P42, I43, W47, T240, } \\
\text { A24I, W242 }\end{array}$ \\
\hline $\begin{array}{l}\alpha \text {-toxin (bacterial phospholipase } \\
\text { C) }\end{array}$ & lcal & Y33I, F334 & Fn & {$[102]$} & -4.5 & 2.2 & $\begin{array}{l}\mathrm{V} 143, \mathrm{~A} 146, \mathrm{M} 210 \\
\mathrm{~W} 214, \mathrm{Y} 33 \mathrm{I}, \mathrm{F} 334\end{array}$ \\
\hline I5-lipoxygenase & $\underline{\| l o x}$ & $\frac{\mathrm{Y} I 5}{\mathrm{LI}}, \underline{\mathrm{F70}}, \mathbf{L 7 I}, \mathrm{W} / 8 / \mathrm{c}$ & $\mathrm{Bn}$ & {$[103]$} & -7.4 & 6.3 & $\begin{array}{l}\text { L7I, II 94, LI 95, L29I, } \\
\text { Y292, F4I2 }\end{array}$ \\
\hline 8R-lipoxygenase & $\underline{\mathrm{zq} 4}$ & W4I3, W449 & $\mathrm{FL}, \mathrm{Fn}$ & {$[104]$} & -5.0 & 5.9 & $\begin{array}{l}\text { W413, F414, Y448, } \\
\text { W449, V560, M570 }\end{array}$ \\
\hline
\end{tabular}


Table I: Comparison of membrane-bound residues in peripheral proteins according to experimental studies and calculations peripheral proteins. (Continued)

\begin{tabular}{|c|c|c|c|c|c|c|c|}
\hline Cholesterol oxidase & Icoy & M8I & FLq & {$[105]$} & -4.1 & 5.3 & $\begin{array}{l}\text { M8I, M332, W333, } \\
\text { L369, Y372 }\end{array}$ \\
\hline Signal peptidase & $\underline{1 \mathrm{kn} 9}$ & W300 & $\mathrm{Fn}$ & {$[106]$} & -4.5 & 4.5 & $\begin{array}{l}\text { W300, M30I, F303, } \\
\text { L3|4, L316 }\end{array}$ \\
\hline Synapsin I & $\underline{\text { lauv }}$ & $\begin{array}{l}\text { Regions } 166-192,233- \\
258,278-327\end{array}$ & $\mathrm{CL}$ & {$[107]$} & -4.4 & 2.5 & LI68, V I 72, L297 \\
\hline$\alpha$-synuclein & $\underline{1 \times q 8}$ & $\begin{array}{l}\text { T59, V63, G67, V70, } \\
\text { V74, V77, T81, A85, } \\
\text { A89 }\end{array}$ & SL & {$[108]$} & -22.8 & 17.9 & $\begin{array}{l}\text { T59, V63, V66, G67, } \\
\text { V70, V74, V77, A78, } \\
\text { T81, A85, I88, A89 }\end{array}$ \\
\hline Perfringolysin & Ipfo & W466 & $\mathrm{Bn}$ & [109] & -5.5 & 3.4 & $\begin{array}{l}\text { L462, W466, L49I, } \\
\text { Y492 }\end{array}$ \\
\hline Daptomycin & $1+5 n$ & Kyn I4 & $\mathrm{FL}$ & {$[110]$} & -9.8 & 4.9 & Dka I, W2, Kyn I4 \\
\hline Lactoferricin B & $\underline{\text { Ilfc }}$ & W6, W8 & $\mathrm{FL}$ & {$[111]$} & -4.6 & 5.3 & W6, W8, LI3-PI6, II8 \\
\hline Hanatoxin & $\underline{I d l h}$ & W30 & FLq & {$[112]$} & -2.5 & 3.9 & Y4, L5, F6, W30 \\
\hline Subtilosin & $I p \times q$ & W34 & $\mathrm{FL}$ & [113] & -6.7 & 5.1 & F22, F3I, W34 \\
\hline
\end{tabular}

a $\mathrm{Bn}$ - based on membrane binding affinities of mutants; SL - spin-labeling data based on depth parameters $\Phi$ (SL* - based only on exposure of labels to polar probes); FL - fluorescence; FLq - fluorescence quenching; Fn - functional studies of mutants; $\mathrm{CL}$ - chemical labeling. Underlined residues are located in the lipid headgroup region, close to the hydrophobic boundaries. Coinciding residues in two sets are shown as bold. b $\Delta G_{\text {calc }}$, calculated binding energies $(\mathrm{kcal} / \mathrm{mol}) ; D(\AA)$ maximal penetration depths of atoms into the hydrocarbon core. Residues penetrating into lipid acyl chain region are identified based on locations of side-chain atoms or NH hydrogens (when compared with NMR data).

cWI8I is missing in the crystal structure.

d Data for a homologous protein

determined. These residues either contribute significantly to the membrane binding affinity, as evident from mutagenesis studies, or become inaccessible to water during the protein-membrane association, which can be detected by different physico-chemical methods. Two especially informative methods are site-directed spin labeling (SDSL) and fluorescence quenching, because they allow measuring the membrane penetration depths of individual amino acid residues. Table 2 includes proteins whose overall orientations and membrane-interaction regions have been evaluated by solution or solid-state NMR, fluorescence, or FTIR spectroscopy.

A comparison with experimental data demonstrates that membrane penetration depths, overall orientations of the proteins, and the sets of their lipid-embedded residues are predicted correctly. The experimentally determined sets of membrane-penetrating residues may be smaller than the sets obtained in calculations (Table 1), mainly because some of the predicted membrane-embedded residues have not been experimentally tested. Importantly, the calculated orientations of homologous proteins in the membrane were always similar, though not identical (Figures $1,2,5,6)$.

All proteins considered can be separated into two major categories: (1) lipid clamps with cavities or pockets that serve for specific binding of headgroups of certain lipids (Figures 1, 2, 3, 4); and (2) other proteins that interact with lipid bilayers non-specifically (Figures 5, 6, 7). Lipid clamps serve for targeting of proteins to the appropriate cellular membranes rich in the corresponding lipids. For example, binding of $\mathrm{PI}(4,5) \mathrm{P}_{2}, \mathrm{PI}(3) \mathrm{P}, \mathrm{PI}(3,5) \mathrm{P}_{2}$, or $\mathrm{PI}(4) \mathrm{P}$ lipids may target the corresponding domains to the plasma membrane, early endosome, late endosome, or Golgi, respectively [4].

Due to the presence of a few solvent-exposed hydrophobic residues, lipid clamps can be positioned on the membrane surface using our method. However, the binding energies of lipid clamps appear to be small ( -2 to $-7 \mathrm{kcal} /$ mol, Table 1). This is in agreement with weak affinity of such proteins to artificial membranes in the absence of their cognate lipids, for which the transfer energies are often below the experimental detection threshold of 3-4 $\mathrm{kcal} / \mathrm{mol}$. However, in most cases these hydrophobic interactions were sufficient to properly define the orientations of the proteins, which are in good agreement with known experimental data (see below).

Some lipid clamps have been crystallized with headgroup analogues of their cognate lipids. In these cases acyl chains of the bound lipids were modeled to check whether the overall orientation of proteins may be affected by the presence of bound lipids (see Methods). It appears that calculated spatial positions of these proteins in membranes are usually similar with and without reconstructed lipids. Two exceptions are the EEA1-FYVE dimer and P47phox_PX domain, whose orientations are significantly altered by the bound lipids (Figures 2B, 3B). Different orientations of these two proteins in the presence and absence of their cognate lipids are consistent with experimental studies $[39,40,88]$. Moreover, the orientation of EEA1-FYVE is influenced by its dimerization [10], whereas 
Table 2: Predicted penetration depths $(D)$ and binding energies $\left(\Delta G_{\text {calc }}\right)$ of peripheral proteins and peptides, whose overall orientations or penetration depths in the lipid bilayer have been experimentally evaluated.

\begin{tabular}{|c|c|c|c|c|c|}
\hline Protein & PDB id & $\Delta G_{\text {calc }}(\mathrm{kcal} / \mathrm{mol})$ & $D(\AA ̊)$ & Methoda $^{a}$ & References \\
\hline \multicolumn{6}{|c|}{ Lipid clamps } \\
\hline $\mathrm{Cl}$ domain of protein kinase $\mathrm{C}_{\gamma}$ & $\underline{\text { tbn }}$ & -2.3 & 7.5 & NMR & {$[114]$} \\
\hline Annexin 24 & $\underline{\mathrm{Idk} 5}$ & -1.2 & 1.8 & $\mathrm{FL}$ & {$[115]$} \\
\hline Blood coagulation factor VIla & $\underline{\text { Idan }}$ & -5.7 & 4.8 & $\mathrm{FL}$ & {$[116]$} \\
\hline Seminal plasma protein & $\underline{\ln 8 p}$ & -12.3 & 9.2 & EPR & {$[117]$} \\
\hline \multicolumn{6}{|c|}{ Other proteins } \\
\hline Cardiotoxin III & $\underline{\text { IhOj }}$ & -13.1 & 6.5 & FTIR & {$[118]$} \\
\hline Cytotoxin I & $\underline{\operatorname{ltg} x}$ & -12.4 & 6.8 & $\mathrm{FLq}$ & [119] \\
\hline Cardiotoxin II & $\overrightarrow{\mathrm{Iffj}}$ & -18.1 & 8.7 & NMR & {$[120]$} \\
\hline Sapecin & $\| 4 v$ & -6.6 & 6.1 & NMR & {$[121]$} \\
\hline Cytochrome c & $\underline{\mathrm{Ihrc}}$ & -2.0 & 1.9 & SL, NMR & {$[122,123]$} \\
\hline Coagulation factor IXa & $\underline{I p f x}$ & -3.8 & 3.2 & $\mathrm{FL}$ & {$[124]$} \\
\hline Coagulation factor XIV & $\underline{\text { Ilqv }}$ & -4.9 & 3.5 & $\mathrm{FL}$ & {$[125]$} \\
\hline \multicolumn{6}{|c|}{ Peptides } \\
\hline Alamethicin & $\underline{\text { lamt }}$ & -23.7 & 28.1 & NMR, SL & [44-46] \\
\hline Zervamicin Ilb & $\underline{\operatorname{lin} 9}$ & -14.3 & 9.9 & $\mathrm{FL}$ & [47] \\
\hline Antiamoebin I & $\overline{\text { Ijoh }}$ & -16.4 & 14.4 & $\mathrm{FL}$ & {$[47]$} \\
\hline Magainin & $2 \mathrm{mag}$ & -14.5 & 10.1 & NMR, FL & {$[126,127]$} \\
\hline Nisin & Iwco & -4.0 & 8.8 & NMR & {$[128]$} \\
\hline Neuropeptide $Y$ & $\underline{\text { licy }}$ & -9.4 & 9.4 & $\mathrm{SL}$ & {$[129]$} \\
\hline Mersacidin & $\underline{\mathrm{Imqz}}$ & -4.9 & 3.5 & NMR & {$[130]$} \\
\hline
\end{tabular}

aAs in Table I; FTIR - ATR FTIR spectroscopy.

membrane-protein interactions of P47phox-PX domain depend on conformational changes due to protein phosphorylation $[38,39]$.

The majority of peripheral proteins, which have nonpolar patches and thus can be treated by our method, do not belong to the lipid clamps category (Tables 1, 2, 3). These proteins are usually attached to the membrane primarily by hydrophobic interactions of exposed non-polar residues (Tables 1 and 2), which penetrate to the hydrocarbon core region. Calculated energies of these proteins are significant (from -5 to $-20 \mathrm{kcal} / \mathrm{mol}$; Tables $1,2,3$ ). On the other hand, there are cationic proteins that use electrostatics as a means of membrane binding or targeting [4,17-22]. Some of these can still be treated by our method, such as cytochrome $\mathrm{c}$ and charybdotoxin from our dataset (Table 4). Some proteins that bind through hydrophobic interactions, such as $\mathrm{C} 2$ domain or $\mathrm{CPLA}_{2}$ or lipoxigenase, also require $\mathrm{Ca}^{2+}$ binding, which may interact with lipid phosphates $[5,34,37]$ or work as an electrostatic switch [33].
Locations of bound lipids, $\mathrm{Ca}^{2+}$ ions, exposed hydrophobic, basic and aromatic residues

The predicted membrane boundaries are consistent with positions of crystallized lipids in the protein structures. The carbonyl groups of the anchoring lipids are located close to the boundaries of the acyl chain region (blue or red dots in Figures 1, 2, 3, 4, 5, 6, 7, 8), whereas phosphate groups of the bound lipids correspond to the layer of phosphate groups in the surrounding bilayer (gold dots in Figures 1, 2, 3, 4, 5, 6, 7, 8). Thus, the protein-bound anchoring lipids are properly aligned with surrounding fluid lipids, which are not explicitly included in the computational model.

Our calculations are also supported by locations of cocrystallized $\mathrm{Ca}^{2+}$ ions. For example, all bound calcium ions of C2 domains are arranged within $2 \AA$ of the layer of lipid phosphate groups (purple spheres and gold dots in Figure 1, respectively). This allows formation of stabilizing ionic bridges between the $\mathrm{Ca}^{2+}$ ions and phosphate groups of surrounding lipids. One such calcium-bridge 


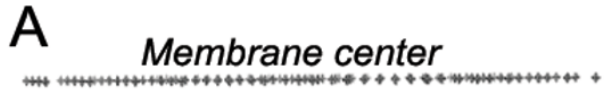

Hydrocarbon core

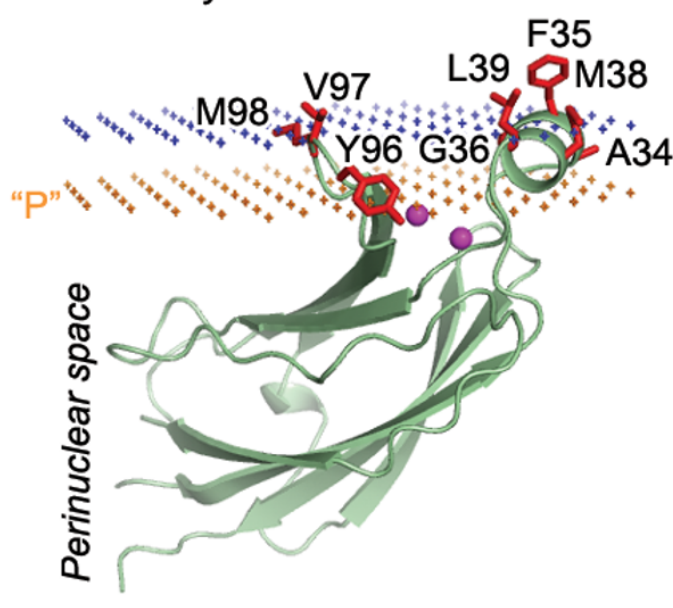

$\mathrm{cPLA}_{2} \alpha-\mathrm{C} 2$ (1rlw)

C Membrane center

Hydrocarbon core

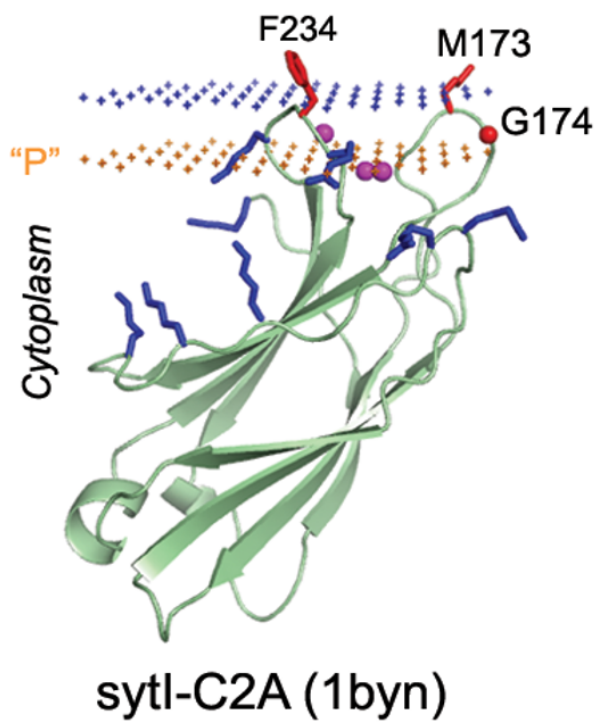

B

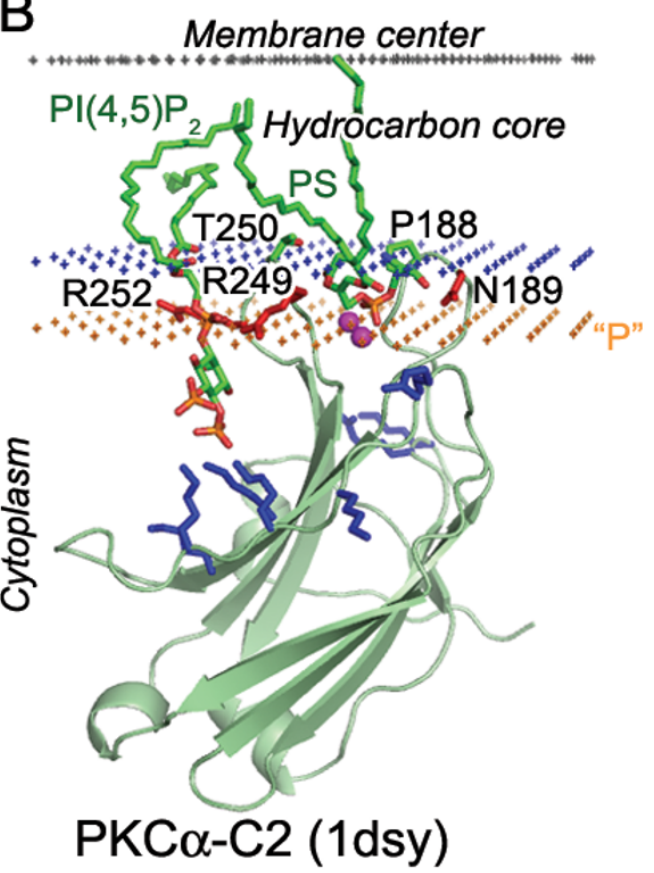

$\mathrm{D}$

Membrane center

Hydrocarbon core

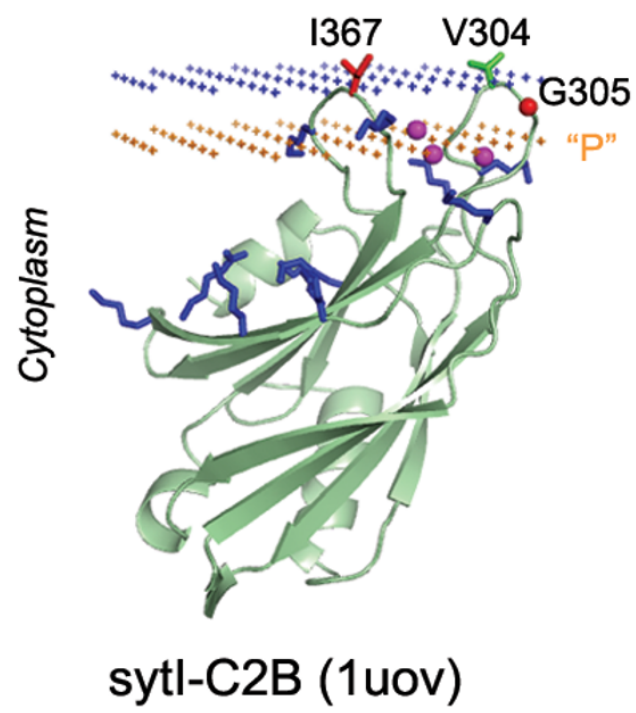

Figure I

Calculated membrane binding modes for C2 domains of $\mathrm{CPLA}_{2 \alpha}(\mathrm{A}), \mathrm{PKC} \alpha-\mathrm{C} 2$ with lipid ligands PS and $\mathrm{PI}(4,5) \mathrm{P}_{2}(B)$, sytl-C2A (C) and sytl-C2B (D). The backbone of $C 2$ domains and the specific lipid ligands are shown in ribbon and stick models, respectively. $\mathrm{Ca}^{2+}$ ions are shown as balls colored magenta. Residues identified as penetrating to a nonpolar environment by SDSL are colored red. Cationic residues involved in ligand binding and membrane interactions are colored blue. The hydrocarbon core boundary at the cytoplasmic side is indicated by blue dots. The layer of lipid phosphates ("P") is shown by gold dots (at $5 \AA$ outside the hydrocarbon boundary [28]). The center of the membrane is indicated by grey dots (at $15 \AA$ inside the boundary). All Figures were generated by PyMol. 

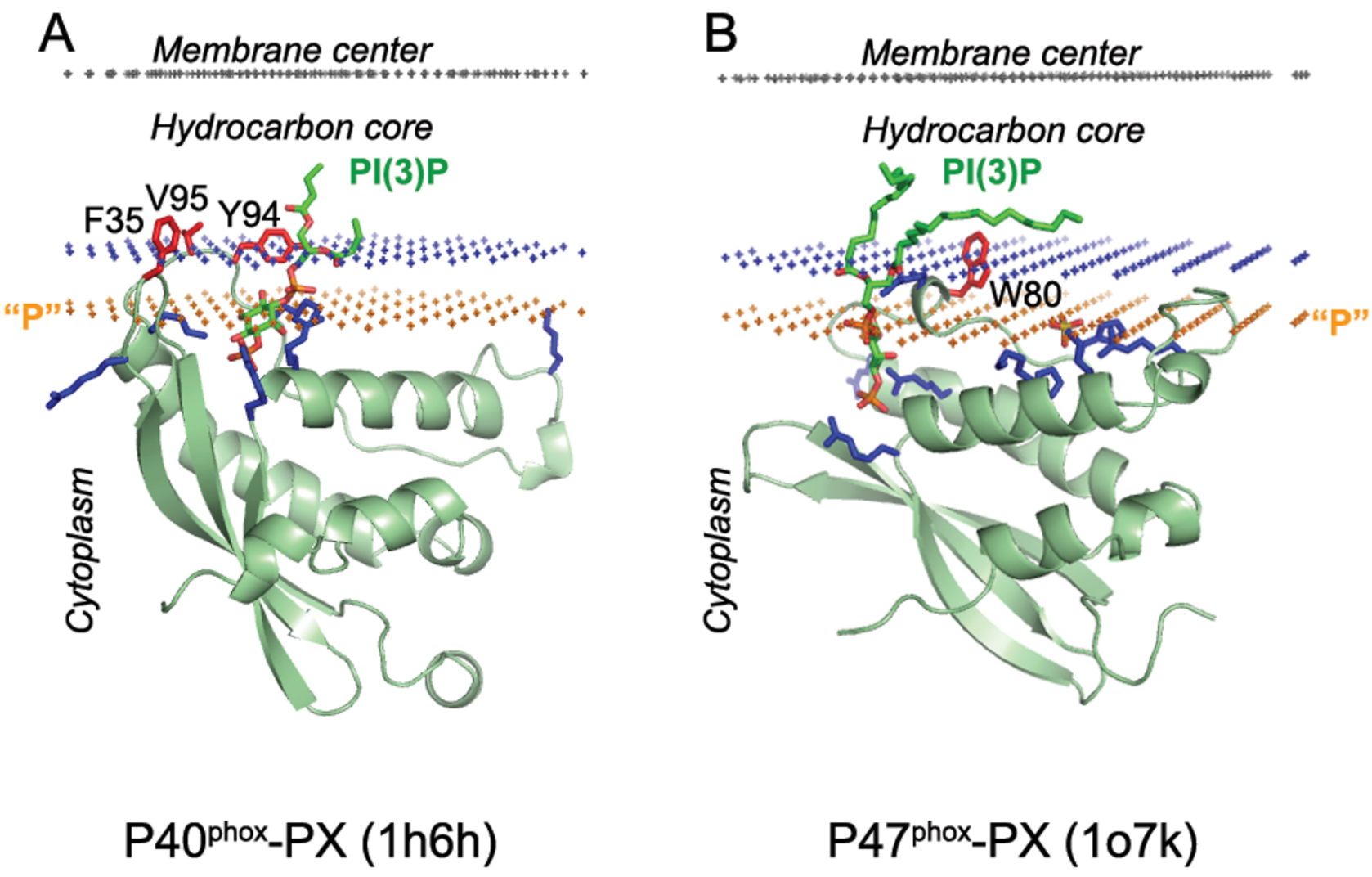

\begin{abstract}
Figure 2
Calculated membrane binding modes for PX domains of P40phox with lipid ligand PI(3)P (A) and P47phox with lipid ligand $\mathbf{P I}(\mathbf{3}, \mathbf{4}) \mathbf{P}_{\mathbf{2}}(\mathbf{B})$. The backbone of PX domains and the specific lipid ligands are shown in ribbon and stick model, respectively. Residues identified as penetrating to the membrane in mutagenesis and binding experiments are colored red. Cationic residues involved in ligand binding and membrane interactions are colored blue. Hydrocarbon core boundary at the cytoplasmic side is indicated by blue dots. The layer of lipid phosphates ("P") is shown by gold dots (at $5 \AA$ outside the hydrocarbon boundary). The center of membrane is indicated by grey dots (at $15 \AA$ inside the boundary).
\end{abstract}

can be seen in the crystal structure of PKC $\alpha-\mathrm{C} 2$ domain in complex with PS (Figure 1B). According to our results, $\mathrm{Ca}^{2+}$ ions observed in crystal structures of many other proteins, such as phospholipases A2, some lipases, lipoxygenases, $\alpha$-toxins, and annexin, also appear to be located at the level of lipid phosphates. The possible involvement of $\mathrm{Ca}^{2+}$ ions in interactions with lipid phosphates has been previously discussed $[5,33,34,37]$.

Two other important features are positions of exposed hydrophobic and charged residues of the proteins with respect to the membrane. All exposed non-polar residues and the acyl chains of bound lipids are inserted in the hydrocarbon core of the lipid bilayer (Figures 1, 2, 3, 4, 5, $6)$. All charged residues are located in the lipid headgroup region outside the calculated hydrocarbon boundaries. A significant part of the positively charged Lys and Arg residues interacts with lipid phosphates at a distance of $\sim 5 \AA$ outside the acyl chain boundaries [28]. Other Lys and Arg residues remain in the aqueous solution at larger distances from the hydrocarbon boundaries and may interact with the negatively charged membrane surface electrostatically or may form ionic pairs with distal phosphates of phosphoinositides (Figures 1).

It is noteworthy that Trp residues of peripheral proteins are frequently involved in the membrane binding (Table 1 ). According to our results, Trp side chains are usually located at the hydrocarbon boundary, although they can also be found in the membrane interfacial region. Their indole rings are often buried in the hydrocarbon core, while their NH group "snorkels" into the water-saturated interface (Figures 2B, 4A, 5, 7). This provides an additional gain of transfer energy. Such arrangement of Trp residues at the water-hydrocarbon boundary (i.e. at a distances of $15 \AA$ from the membrane center) has been 

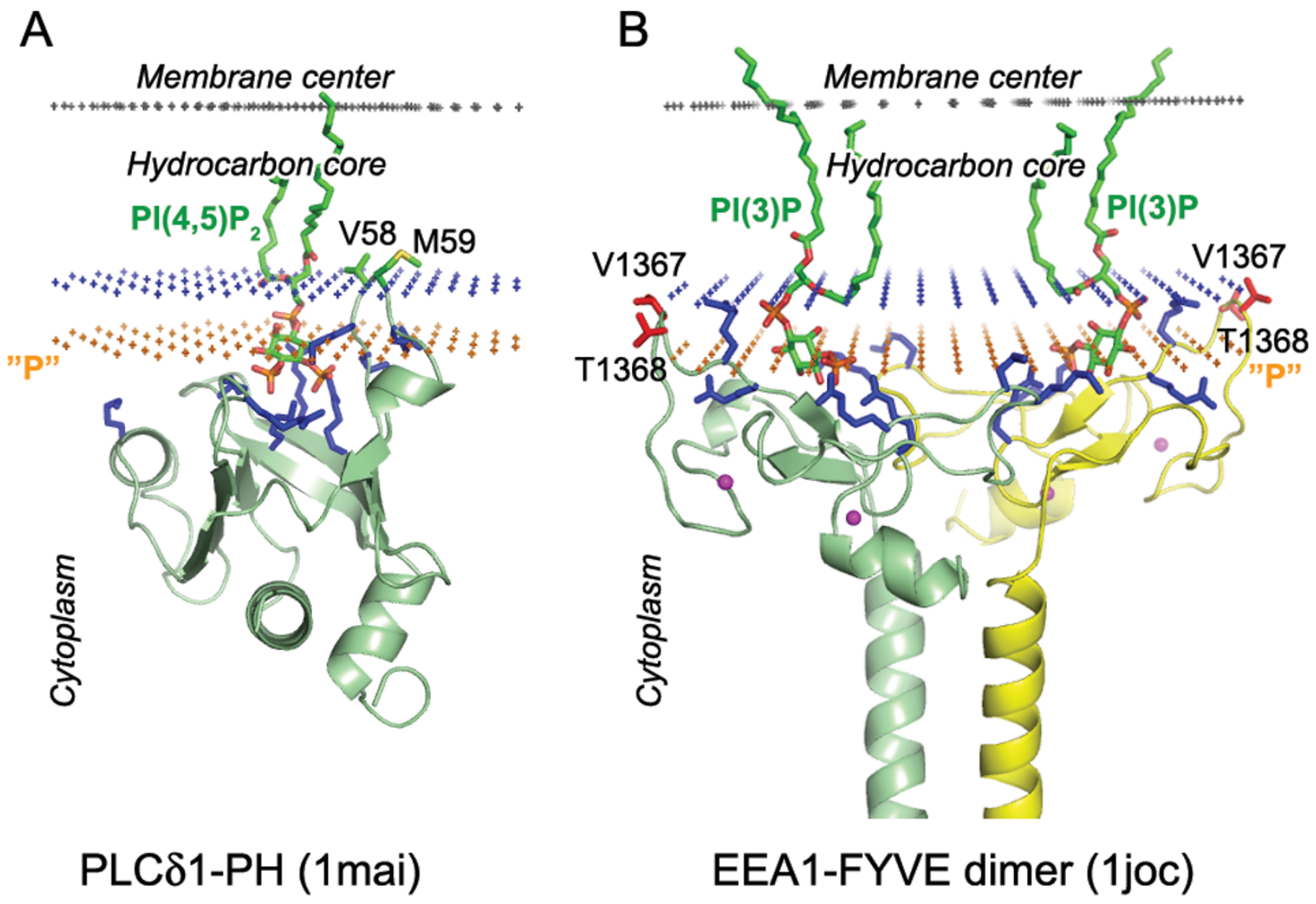

Figure 3

Calculated membrane binding modes for PH domain of PLC $\delta$ I with lipid ligand PI(4,5)P 2 (A) and EEAI-FYVE domain with lipid ligand PI(3)P (B). The backbone of two domains and the specific lipid ligands are shown in ribbon and stick model, respectively. Residues identified as penetrating the non-polar interior of micelles by NMR (and also shown to be important for membrane binding) are colored red. $\mathrm{Zn}^{2+}$ ions (FYVE domain) are shown as balls colored magenta. Cationic residues involved in ligand and membrane interactions are colored blue. Hydrocarbon core boundary at the cytoplasmic side is indicated by blue dots. The layer of lipid phosphates ("P") is shown by gold dots (at $5 \AA$ outside the hydrocarbon boundary). The center of membrane is indicated by grey dots (at $15 \AA$ inside the boundary).

observed in transmembrane proteins [29], and it is energetically preferred in model $\alpha$-helical peptides [30]. Furthermore, the tryptophan analogue 3-methyl-indole accumulates primarily in the same region of the lipid bilayer [31,32].

\section{C2 domains}

Spatial positions of twenty different C2 domains with pairwise sequence identities less than 30\% were calculated and deposited in OPM. Ten of these proteins were previously included into a dataset of membrane-binding proteins [62]. All C2 domains interact with the membrane via two $\mathrm{Ca}^{2+}$ - binding loops with exposed hydrophobic residues [33]. Calculated tilts of these domains relative to the membrane normal vary from 20 to $60^{\circ}$.
The spatial positions of four $\mathrm{C} 2$ domains in membrane (Figure 1) have been extensively studied using SDSL. This approach allows evaluation of membrane penetration depths of individual spin-labeled Cys residues by measuring their EPR saturation parameters in the presence of non-polar and polar paramagnetic probes, such as molecular oxygen and NiEDa, respectively [34]. The membrane depth parameter $(\Phi)$ is determined from the ratio of accessibilities of the nitroxyl label to the non-polar and polar probes. This parameter is equal to zero at the hydrophobic boundary, where the effective concentrations of polar and non-polar probes are approximately equal, and it is positive inside the acyl chain region $[6,7,35,36]$, which is consistent with our previous results for several transmembrane proteins [26]. 

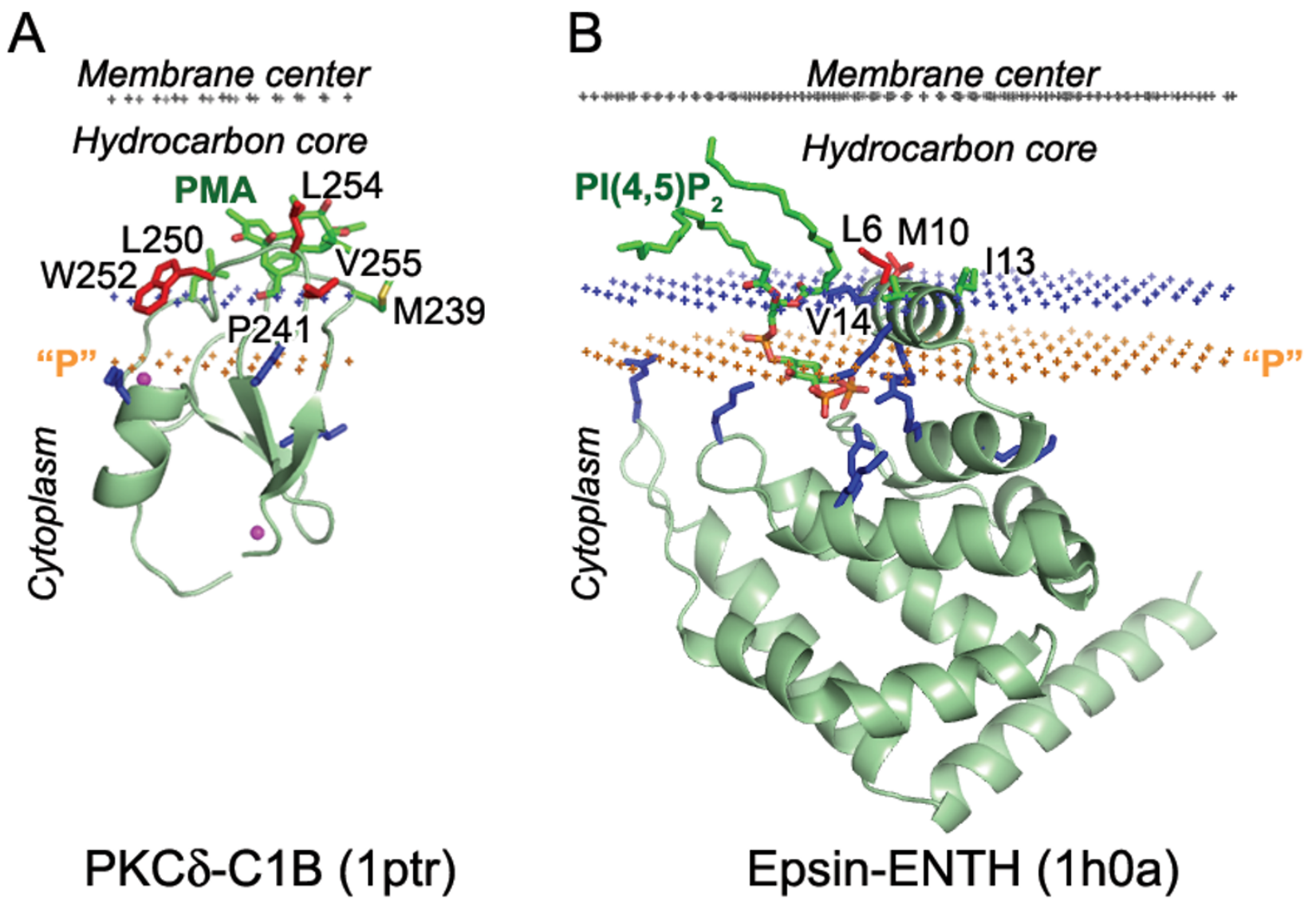

\section{Figure 4}

Calculated membrane binding modes for CIB domain of PLC $\delta$ with phorbol ester PMA (A) and Epsin-ENTH domain with lipid ligand $\mathbf{P I}(\mathbf{4 , 5}) \mathbf{P}_{\mathbf{2}}(\mathbf{B})$. The backbone of two $\mathrm{H}$-type domains and the specific lipid ligands are shown in ribbon and stick model, respectively. Residues identified as penetrating to the membrane in mutagenesis and binding experiments are colored red. $\mathrm{Zn}^{2+}$ ions ( $\mathrm{Cl}$ domain) shown as balls colored magenta. Cationic residues involved in ligand and membrane interactions are colored blue. Hydrocarbon core boundary at the cytoplasmic side is indicated by blue dots. The layer of lipid phosphates ("P") is shown by gold dots (at $5 \AA$ outside the hydrocarbon boundary). The center of membrane is indicated by grey dots (at I5 $A$ inside the boundary).

The comparison with SDSL data indicates that positions of $\mathrm{C} 2$ domains are reproduced with reasonable precision. All residues with positive $\Phi$ parameters (indicated by red in all Figures) penetrate the acyl chain region (bold in Table 1) or are situated close to calculated hydrocarbon boundaries in the membrane interface (underlined in Table 1). The latter residues are usually polar or charged (as R249 and R250 of PKC $\alpha-C 2$ domain in Figure 1B) and may actually reach the hydrophobic core after their substitution by the non-polar spin-labeled cysteine. The locations of $\mathrm{Ca}^{2+}$ ions (4-6 $\AA$ outside the acyl chain region, Figure 1) are consistent with X-ray reflectivity and EPR studies [34,37].
We also found that the $\mathrm{C} 2$ domain of cytosolic phospholipase $\mathrm{A}_{2}\left(\mathrm{CPLA}_{2}-\mathrm{C} 2,1 \mathrm{rlw}\right.$, Figure $\left.1 \mathrm{~A}\right)$ interacts more extensively with the hydrophobic core $\left(\Delta \mathrm{G}_{\text {calc }}=-7 \mathrm{kcal} / \mathrm{mol}\right)$ and penetrates the hydrocarbon core by $\sim 2-3 \AA$ deeper than C2-domains of synaptotagmin II (sytI-C2B, 1uov, $\mathrm{G}_{\text {calc }}=-4 \mathrm{kcal} / \mathrm{mol}$ ) and by $\sim 4 \AA$ deeper than the $\mathrm{C} 2$ domain of protein kinase $\mathrm{C} \alpha\left(\mathrm{PKC} \alpha-\mathrm{C} 2,1 \mathrm{dsy}, \Delta \mathrm{G}_{\mathrm{calc}}=-2\right.$ $\mathrm{kcal} / \mathrm{mol}$ ) (Figure 1, Table 1). This is consistent with SDSL data $[33,34]$. The differences in membrane penetration depths correlate with intracellular localizations and lipid binding preferences of corresponding $\mathrm{C} 2$ domains. The most hydrophobic and deeply inserted $\mathrm{CPLA}_{2}-\mathrm{C} 2$ domain preferentially interacts with zwitterionic PC-rich mem- 


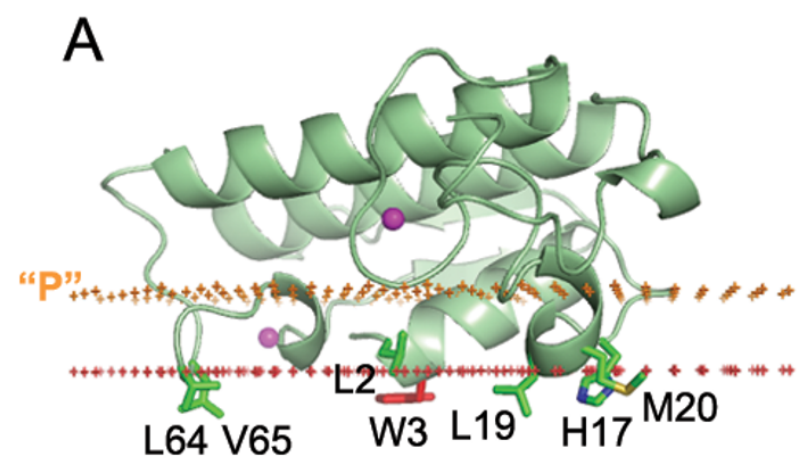

Hydrocarbon core

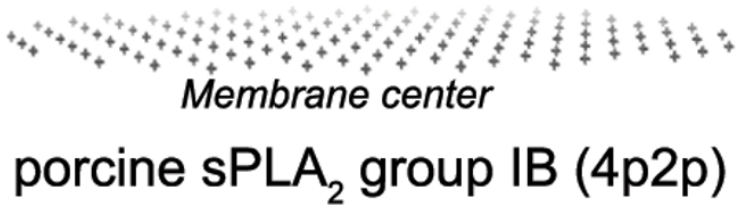

B
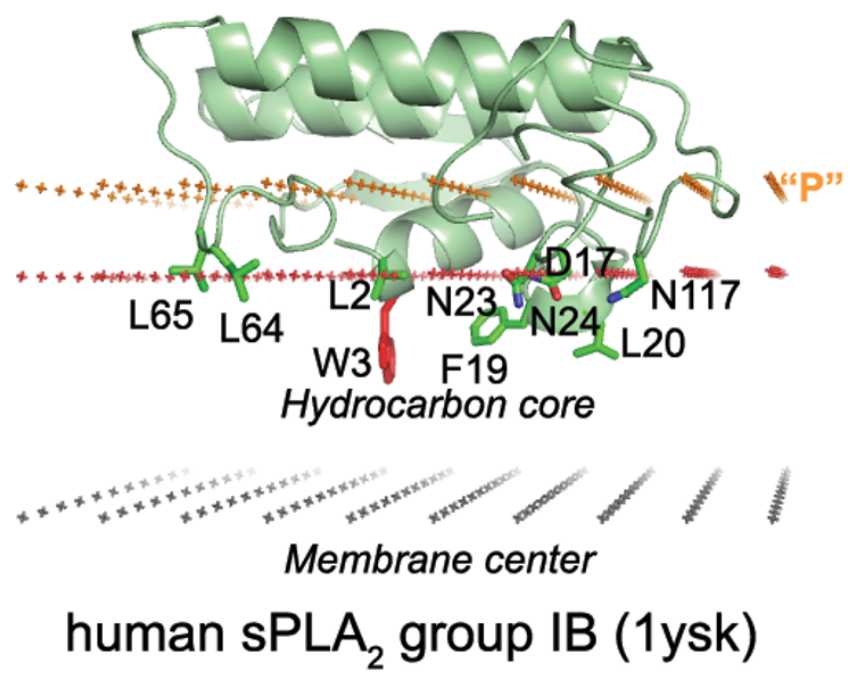

\section{Figure 5}

Positions of two homologous phospholipases in the lipid bilayer. $(A)$ position of porcine pancreatic sPLA $\mathrm{A}_{2}$ calculated by PPM, and (B) experimentally defined arrangement of human pancreatic SPLA 2 . (a homology model, lysk PDB entry) studied by ATR FTIR spectroscopy [I I]. Trp residues identified as penetrating the non-polar environment by fluorescence quenching are colored red. $\mathrm{Ca}^{2+}$ ions are shown as balls colored magenta. Hydrocarbon core boundary at the extracellular side is indicated by red dots. The layer of lipid phosphates ("P") is shown by gold dots (at $5 \AA$ outside the hydrocarbon boundary). The center of membrane is indicated by grey dots (at $15 \AA$ inside the boundary). The obtained orientations are quite similar, but the model of human sPLA $(B)$ penetrates slightly deeper and with a slightly different $\left(\right.$ by $\left.\sim 10^{\circ}\right)$ tilt into the membrane interior. Therefore, N23, N24, NI 17, which were localized outside hydrophobic boundaries by our method (A), appeared to be immersed into the hydrophobic slab in the experimentally-derived position of the protein (B).

branes, whereas others interact with anionic or PS-rich membranes [4]. For example, PKC $\alpha$-C2 forms a stable complex with PS as shown in Figure 1B. PS-specific C2 domains are known to interact simultaneously with two types of anionic lipids: they have a binding pocket for PS itself and a cluster of positively charged residues that binds phosphate groups of phosphoinositides (PI) [33]. As shown in Figure 1B, the P4 and P5 atoms of PI are situated at a larger distance from the hydrocarbon boundary ( $\sim 12 \AA)$ than the P1 phosphate atom of PS ( $5 \AA$ ). The formation of several ionic bridges with two lipid molecules stabilizes the significant protein tilt with respect to the membrane normal.

\section{PX domains}

OPM includes five different PX domains, which have similar orientations in lipid-bound form. However, the position of the P47phox-PX domain in the membrane is different in the ligand-free conformation, and it is largely regulated by the conformational rearrangement caused by phosophorylation and movement of C-terminal fragment $[38,39]$. Figure 2 demonstrates spatial positions of two PX domains of NADH oxidase, P40phox_PX and P47phox_PX, in the lipid-bound conformation. Exposed hydrophobic residues of PX domains, which penetrate into the hydrophobic core in our calculations, were shown to be important for membrane binding (indicated by red in Figure 2, "Bn" data in Table 1).

\section{PH domains}

Twenty nine different $\mathrm{PH}$ domains are currently included in OPM. Among them are eleven domains previously included in a dataset of membrane-binding proteins [62]. Orientation of PLC $\delta 1$ PH-domain was identical when calculated with and without bound lipid. Two exposed nonpolar residues (V58 and M59) are probably essential for positioning of this domain in the hydrocarbon core region (Figure 3A). Some PH domains from the PDB were not included into OPM, because their calculated energy was close to zero, i.e. calculation did not show any preferential mode of their association with membrane. As was noted before, a large number of $\mathrm{PH}$ domains do not bind membranes $[20,62]$. This may be attributed to several possible reasons: (a) some PH domains probably do not associate with lipid bilayers, but rather interact with other proteins; (b) membrane-interacting loops of $\mathrm{PH}$ domains 


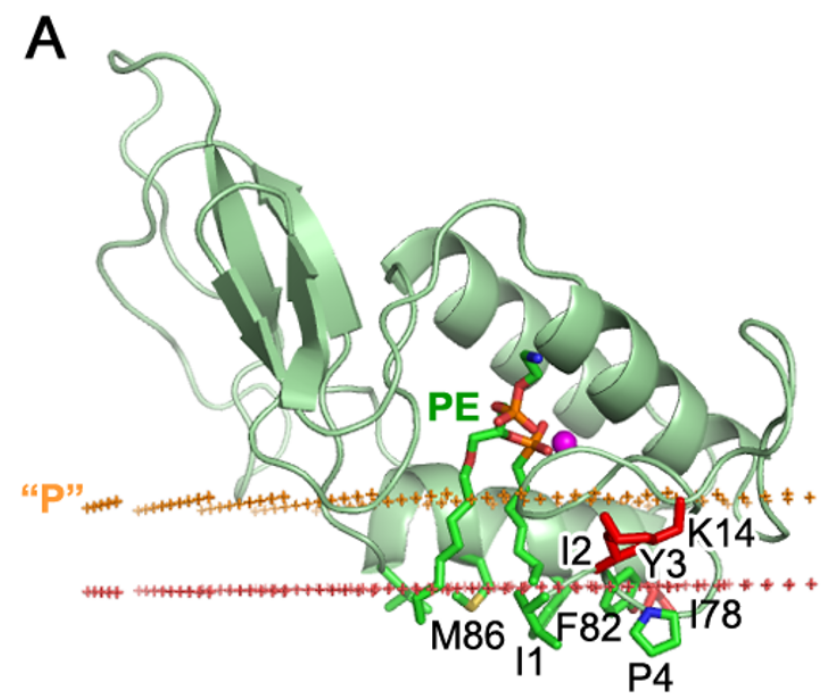

Hydrocarbon core

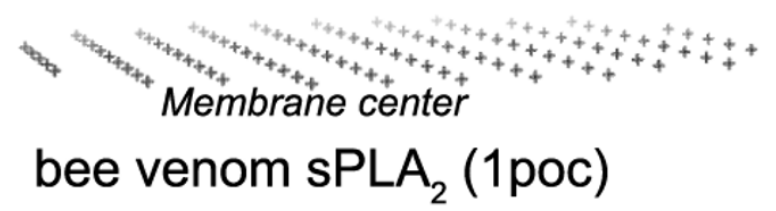

B

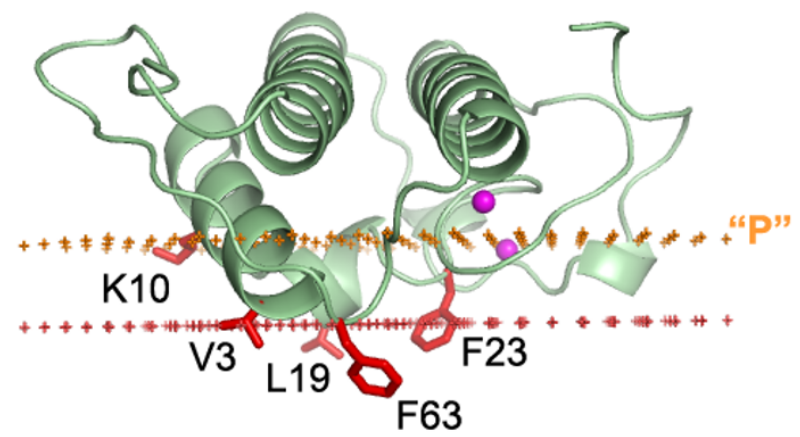

Hydrocarbon core

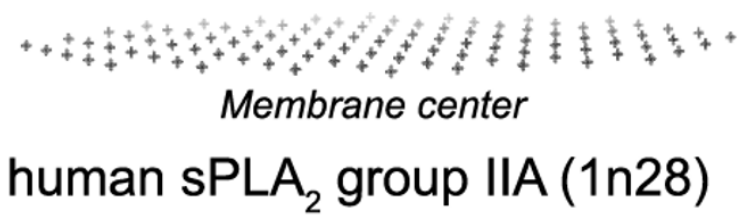

\section{Figure 6}

Calculated membrane binding modes for sPLA from bee venom with a transition state PE analogue (A) and human group IIA sPLA $(\mathbf{B})$. The backbone of two proteins and the specific lipid ligands are shown in ribbon and stick model, respectively. Residues identified as poorly accessible to polar reagents by SDSL are colored red. $\mathrm{Ca}^{2+}$ ions are shown as balls colored magenta. Hydrocarbon core boundary at the extracellular side is indicated by red dots. The layer of lipid phosphates ("P") is shown by gold dots (at $5 \AA$ outside the hydrocarbon boundary). The center of membrane is indicated by grey dots (at $15 \AA$ inside the boundary).

are disordered or missing, especially in NMR models; and (c) the orientation could not be properly determined without the anchoring lipid.

\section{FYVE domains}

Currently, five different FYVE domains are included in the OPM database. Positions of EEA1-FYVE domains are consistent with data about the importance of hydrophobic residues from their "turret" loop (V1367 and T1368 residues shown in Figure 3B). According to solution NMR studies of the monomeric EEA1-FYVE domain hydrophobic residues from this loop penetrate into the hydrocarbon interior of micelles $[10,40]$. Surprisingly, the calculated tilt with respect to the membrane plane of monomeric and dimeric FYVE domains differed by $\sim 40^{\circ}$ (monomeric 1hyi vs. dimeric 1joc PDB entries), although the same residues from the "turret" loop were buried in the hydrocarbon core in both cases (Figure 3B and 1hyi in Table 1). Thus, the tilt of EEA1-FYVE domain in the membrane is regulated by domain dimerization, in addition to the presence of exposed hydrophobic residues and the specific binding of PI(3)P lipid.

\section{$\mathrm{CI}$ domains and ENTH domain of epsin}

Some of the membrane-targeting domains have a significant number of exposed hydrophobic residues, such as the previously mentioned $\mathrm{CPLA}_{2 \alpha}-\mathrm{C} 2$ (Figure $1 \mathrm{~A}$ ), as well as $\mathrm{PKC} \delta$-C1B and epsin-ENTH domains (Figure 4). According to our calculations, C1 domains penetrate deeper into the hydrocarbon core than other membranetargeting domains, which provides a more significant contribution of hydrophobic interactions $(-5$ to $-6 \mathrm{kcal} / \mathrm{mol}$, Table 1). This is consistent with the binding studies of corresponding C1 domain mutants [89] (shown by red stick in Figure 4).

\section{Phospholipases $A_{2}$}

Membrane enzymes, such as phospholipases A and C, lipoxygenases, fungal lipases, or cholesterol oxidase, strongly associate with lipid bilayers to extract their 


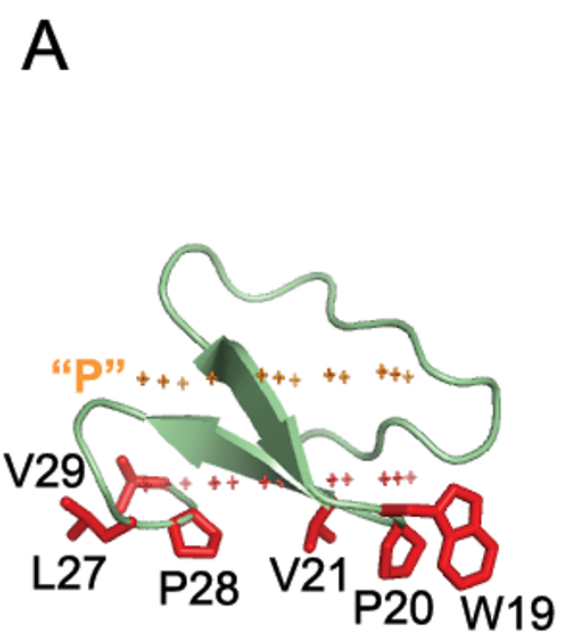

Hydrocarbon core

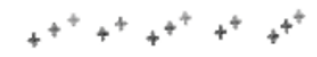

$$
\begin{aligned}
& \text { Membrane center } \\
& \text { Kalata-B1 (1nb1) }
\end{aligned}
$$

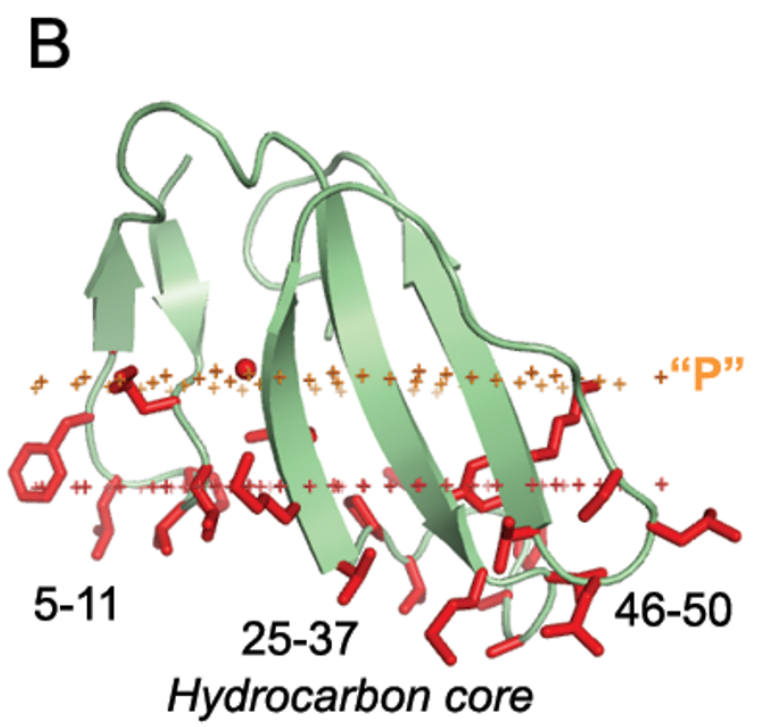

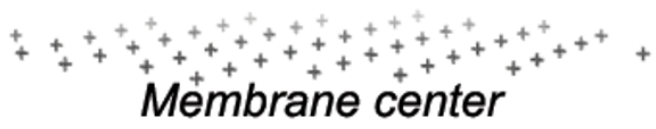

Snake venom toxin (1ffj)

\section{Figure 7}

Calculated membrane binding modes for kalata-B I plant toxin from cyclotide family (A) and cobra P-type cardiotoxin (B). The backbone of two proteins is shown in ribbon model. Micelle-embedded residues identified by solution NMR are colored red. Hydrocarbon core boundary at the extracellular side is indicated by red dots. The layer of lipid phosphates ("P") located $5 \AA$ outside the hydrocarbon boundary is indicated by gold dots, the center of membrane located I $5 \AA$ inside the boundary is indicated by grey dots.

hydrophobic substrates (Tables 1, 2, 3). For example, secreted phospholipase $\mathrm{A}_{2}$ pulls a phospholipid molecule from the membrane by $\sim 4 \AA$ (Figure 6A). It is generally assumed that the lipid-binding "i-face" of secreted phospholipase $\mathrm{A}_{2}$ in the membrane-bound state displaces up to 30 molecules of the surrounding lipids and becomes completely desolvated due to strong hydrophobic interactions with bilayer interior [41]. This is consistent with our results.

The current version of the OPM database includes thirty one secreted phospholipases $\mathrm{A}_{2}\left(\mathrm{sPLA}_{2}\right)$. The calculated spatial position of the porcine pancreatic phospholipase, $\mathrm{sPLA}_{2}$ group IB (Figure 5A) is quite similar to an arrangement that has been proposed based on the results of fluorescence quenching and ATR FTIR spectroscopy data for a closely related human phospholipase $\mathrm{A}_{2}$, whose $3 \mathrm{D}$ structure was modeled by homology (Figure 5B) [11]. The results for two other phospholipases are also consistent with experimental data (Figure 6, Table 1). Several lipidfacing residues of these phospholipases were found to be poorly accessible to the polar and non-polar probes. Therefore, it was suggested that these residues possibly face the interfacial region, rather than interact with the hydrocarbon region $[42,43]$. However, according to our results, these residues pass through the interfacial region and penetrate to the acyl chain region. This is consistent with analysis of fluorescence quenching data and desolvation of i-face of different $A_{2}$ phospholipases $[11,41]$.

Proteins that associate non-specifically with lipid bilayers

Many proteins have extensive clusters of exposed nonpolar residues that penetrate to the hydrophobic core of the lipid bilayer, according to our results. These proteins include integral monotopic domains, amphiphatic antibacterial peptides, lipopeptide antibiotics (e.g. daptomy- 
Table 3: Predicted penetration depths $(D)$ and binding energies $\left(\Delta G_{\text {calc }}\right)$ of peripheral proteins, whose orientations with respect to the membrane have been previously suggested based on their 3D structures

\begin{tabular}{|c|c|c|c|c|}
\hline Protein & PDB id & $\Delta \boldsymbol{G}_{\text {calc }}(\mathrm{kcal} / \mathrm{mol})$ & $D(\AA ̊)$ & References \\
\hline \multicolumn{5}{|c|}{ Lipid clamps } \\
\hline GRK2 kinase $-\beta \gamma$ complex & $\underline{2 b c j}$ & -5.5 & 5.0 & {$[|3|]$} \\
\hline Seminal plasma protein & Ih8p & -12.3 & 9.2 & {$[132]$} \\
\hline Myotubularin-related protein & $\underline{\mathrm{Izvr}}$ & -2.3 & 2.9 & [133] \\
\hline \multicolumn{5}{|c|}{ Other proteins } \\
\hline Fatty acid amine hydrolase & $1 \mathrm{mt} 5$ & -30.8 & 10.0 & {$[134]$} \\
\hline Signal peptidase & $\underline{1 \mathrm{kn} 9}$ & -4.5 & 4.5 & [135] \\
\hline Lanosterol synthase & Iw6k & -19.9 & 6.5 & {$[136]$} \\
\hline Monoamine oxidase & $\underline{105 w}$ & -19.9 & 6.5 & {$[137]$} \\
\hline Prostaglandin E synthase & $\underline{I z 9 h}$ & -13.1 & 4.4 & [49] \\
\hline Carnitine O-palmitoyltransferase 2 & $\overline{2 \mathrm{~h} 4 \mathrm{t}}$ & -8.3 & 3.6 & {$[138]$} \\
\hline Major envelope glycoprotein E & $\underline{\text { lok8 }}$ & -9.9 & 4.9 & {$[139]$} \\
\hline Ferrochelatase & $\overline{\mathrm{Ihrk}}$ & -9.2 & 7.2 & {$[140]$} \\
\hline Sphingomyelinase C & $\underline{I z w x}$ & -6.2 & 6.0 & {$[141]$} \\
\hline$\alpha$-Toxin (bacterial phospholipase C) & $\overline{\text { lolp }}$ & -4.8 & 3.3 & [142] \\
\hline$\beta$-glycosidase & Ivff & -6.5 & 3.3 & {$[143]$} \\
\hline Hydroxysteroid dehydrogenase & $1 \mathrm{y} 5 \mathrm{~m}$ & -14.9 & 3.0 & {$[144]$} \\
\hline Carotenoid oxygenase & $\underline{2 \text { biw }}$ & -12.7 & 5.1 & {$[145]$} \\
\hline$\alpha$-Tocopherol transfer protein & $\underline{\text { loiz }}$ & -20.7 & 8.4 & {$[146]$} \\
\hline Phosphatidylinositol transfer protein & $\underline{\text { Iaua }}$ & -14.0 & 7.8 & {$[147]$} \\
\hline Ganglioside GM2 activator & Ipub & -7.8 & 5.2 & {$[148]$} \\
\hline Oxysterol-binding protein & $\underline{\text { zi7 }}$ & -5.9 & 3.0 & [149] \\
\hline Viscotoxin A3 & lokh & -4.0 & 5.8 & {$[150]$} \\
\hline
\end{tabular}

aOther examples include phospholipases $\mathrm{A}_{2}$ and $\mathrm{C}$, microbial and mammalian lipases, annexins, mammalian cytochromes P450, and fatty acid binding proteins [5, II, 48].

bStructures with removed transmembrane helices.

cin), some polypeptide toxins, water-soluble transporters of small non-polar molecules, and enzymes, such as phospholipases or lipoxygenases (Tables 1, 2, 3).

Calculated membrane penetration depths and orientations of these proteins are consistent with fluorescence quenching, binding, and NMR studies (Figure 7 and Table 1 and 2). For example, the tilt angle of alamethicin with respect to the bilayer normal was estimated as $10-20^{\circ}$ [44] while the calculated value was $16 \pm 8^{\circ}$. The energetic differences between the transmembrane and surface orientations of all peptaibols (alamethicin, zervamicin, and antiamoebin, Table 2) were found to be $<3 \mathrm{kcal} / \mathrm{mol}$. The transmembrane orientation was energetically preferred for alamethicin and chrysospermin $\mathrm{C}$, whereas the tilted orientation was more favorable for all other peptaibols, in agreement with fluorescence and NMR studies of the peptaibols [44-47].

\section{Additional test set of proteins}

Orientations of some peripheral proteins in membranes were not investigated directly, but suggested from their crystal structures, presence of acylated residues or other anchoring elements, and indirect biochemical data. These proteins include numerous phospholipases $\mathrm{A}_{2}$ and $\mathrm{C}$, microbial and mammalian lipases, annexins, mammalian cytochromes P450, and a wide variety of proteins that transport small non-polar compounds in the cell $[5,11,48]$. Twenty proteins from this category are included in Table 3. The suggested tentative orientations of all these proteins are consistent with our results, except for the microsomal prostaglandin E synthase [49].

Importantly, the orientation of non-crystallographic symmetry axes in the membrane-bound homo-oligomeric structures may also serve as an internal control. Symmetry axes are usually perpendicular to the membrane, as for example in squalene-hopene cyclase (2sqc), fatty acid amine hydrolase (1mt5), prostaglandin E synthase $(1 \mathrm{z} 9 \mathrm{~h})$, corticosteroid dehydrogenase (1y5m). However, a deviation of $\sim 3^{\circ}$ from the perpendicular direction was observed for the prostaglandin $\mathrm{H} 2$ synthase dimer, since the structures of the protomers are not completely identical. The symmetry axis of monoamine oxidase dimer was 


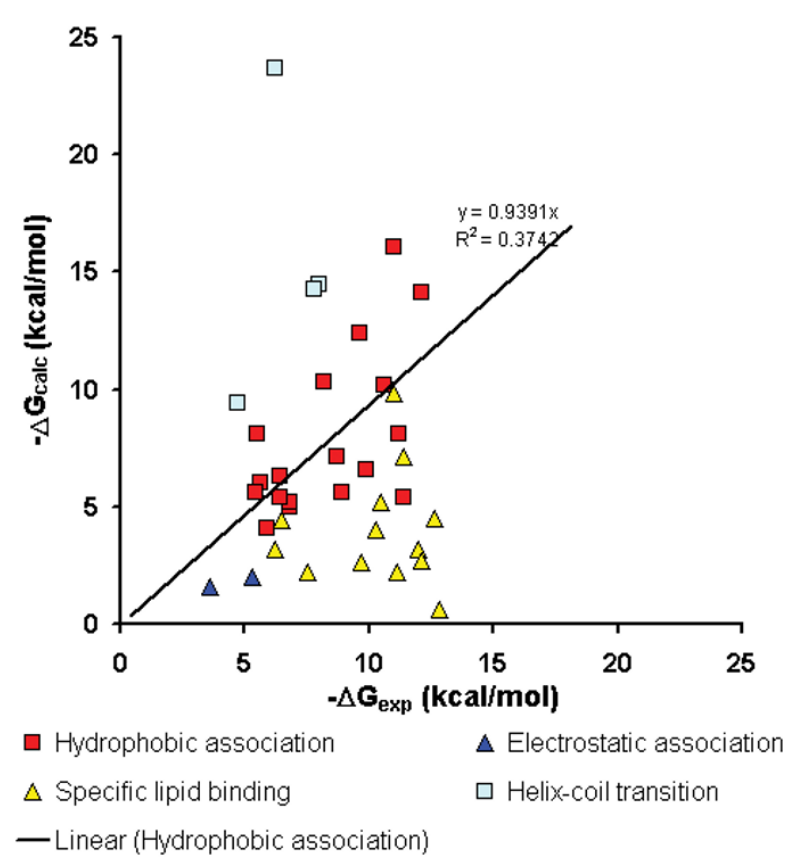

Figure 8

Comparison of calculated $\left(\Delta G_{\text {calc }}\right)$ and experimental $\left(\Delta G_{\text {exp }}\right)$ binding energies for 40 peripheral proteins.

tilted even more (by $\sim 8^{\circ}$ ) with respect to the normal, probably because this enzyme works as a monomer, and the hydrocarbon boundary of the crystallized dimer was poorly approximated by a plane.

\section{Comparison with experimental membrane-binding free energies}

An important question is whether the calculated proteinmembrane binding energies are reasonable. These energies can be compared with experimental membrane binding affinities determined for a number of proteins with known 3D structures (Table 4). All these proteins were separated into several categories depending on their tentative membrane binding mechanisms: (1) nonspecific hydrophobic association; (2) lipid clamps; (3) mostly electrostatic association based on the ionic strength dependence of their membrane binding affinities; and (4) peptides that undergo helix-coil transitions upon association with membranes.

The free energy of protein-membrane association $\left(\Delta G_{b i n d}\right)$ includes several components $[50,51]$ :

$$
\begin{gathered}
\Delta G_{\text {bind }}=\Delta G_{\text {transf }}+\Delta G_{\text {head-group }}+\Delta G_{\text {spec }}+\Delta G_{p K a}+\Delta G_{\text {conf }}+ \\
\Delta G_{\text {bilayer }}+\Delta G_{\text {imm }}
\end{gathered}
$$

where $\Delta G_{\text {transf }}$ is transfer energy of protein atoms from water into the hydrocarbon interior of the membrane;
$\Delta G_{\text {head-group }}$ describes electrostatic, H-bonding and other "non-specific" interactions of the protein with headgroups of fluid lipids; $\Delta G_{s p e c}$ is "specific" binding energy of the lipids, which are inserted as ligands into the protein cavities; $\Delta G_{p K a}$ is an ionization energy of charged groups that lose their charges when transferred from water into the non-polar environment; $\Delta G_{\text {conf }}$ represents changes in thermodynamic stability of the protein during its insertion into the membrane; $\Delta G_{\text {bilayer }}$ is a deformation energy of the lipid bilayer that appears due to non-zero lateral pressure or hydrophobic mismatch; and $\Delta G_{i m m}$ is an immobilization free energy of the protein. The first three terms in this equation usually stabilize the protein-membrane association, while the last four are mostly destabilizing, although the contribution of the lateral pressure ("intrinsic curvature") can be positive or negative [52].

Experimental binding energies of peripheral proteins depend on the specific lipid composition of the membrane [53]. For example, the presence of negatively charged lipids improves the binding of many peripheral proteins. This effect can be attributed to a variety of reasons, including electrostatic attraction of cationic proteins to negatively charged lipids $\left(\Delta G_{\text {head-group }}\right)$, specific binding of anionic lipids to protein cavities $\left(\Delta G_{\text {spec }}\right)$, or reduced lateral pressure and increased hydration in the membrane interfacial region $\left(\Delta G_{\text {bilayer }}\right)$ [51]. For the sake of comparison, we selected only maximal experimental membrane binding affinities of the proteins, which were measured under the lipid compositions most favorable for binding.

Our computational approach includes only transfer and ionization energy contributions ( $\Delta G_{\text {transf }}$ and $\Delta G_{p K a}$ in equation (2)), which are independent of the lipid composition. The hydrocarbon interior of the membrane was treated essentially as non-polar liquid, with interfacial polarity profiles derived from EPR studies. In this approximation, protein-membrane binding is driven by hydrophobic interactions and opposed by desolvation of polar groups and deionization of charged residues. All other energy contributions were temporarily neglected, since they are strongly dependent on the lipid composition ( $\Delta G_{\text {head-group }} \Delta G_{\text {spec }}$ and $\Delta G_{\text {bilayer }}$ ). Therefore, some discrepancies are unavoidable.

Nevertheless, for the majority of proteins from group (1), calculated and experimental energies correlate for proteins from the first group (red squares in Figure 8). The observed differences between calculated and experimental binding energies were relatively small, from 1 to $3 \mathrm{kcal} /$ mol. Thus, in these cases, the non-specific hydrophobic interactions probably account for $~ 50-90 \%$ of experimental binding energies (Table 4). The neglected contributions are either relatively small or cancel each other. 
Table 4: Comparison of calculated binding free energies $\left(\Delta \mathbf{G}_{\mathrm{calc}}\right)$ and maximal experimental $\left(\Delta \mathbf{G}_{\text {exp }}\right)$ binding free energies (kcal/mol) to lipid bilayer for different peripheral proteins.

\begin{tabular}{|c|c|c|c|c|}
\hline Protein name & PDB id & $\Delta \mathbf{G}_{\text {calc }}(\mathbf{k c a l} / \mathbf{m o l})$ & $\Delta \mathbf{G}_{\exp }(\mathbf{k c a l} / \mathrm{mol})^{\mathbf{a}}$ & Reference \\
\hline \multicolumn{5}{|c|}{ Predominantly nonspecific hydrophobic association } \\
\hline Cholesterol oxidase (Brevibacterium) & $\underline{\text { coy }}$ & -4.1 & -5.9 & {$[105]$} \\
\hline Cholesterol oxidase (Streptomyces) & $\underline{\mathrm{Ib} 4 \mathrm{v}}$ & -7.1 & -8.7 & {$[15 \mid]$} \\
\hline 8R-lipoxygenase & $\underline{\mathrm{zq} 4}$ & -5.0 & -6.8 & {$[104]$} \\
\hline Snake phospholipase $A_{2}$, group I & Ipoa & -5.4 & -11.4 & [98] \\
\hline Snake phospholipase $A_{2}$, group II & Ivap & -10.2 & $-10.6 c$ & [98] \\
\hline Human phospholipase $A_{2}$, group II & $\underline{\ln 28}$ & -6.3 & -6.4 & {$[57]$} \\
\hline Voltage sensor toxin & $\underline{156 x}$ & -5.2 & -6.8 & {$[152]$} \\
\hline Kalata BI & $\underline{|\mathrm{nb}|}$ & -5.4 & -6.4 & [153] \\
\hline Phospolipase C & $2 p t d$ & -6.0 & -5.6 & {$[101]$} \\
\hline Insect phospholipase $A_{2}$ & $\underline{\text { Ipoc }}$ & -10.3 & -8.2 & {$[154]$} \\
\hline Human phospholipase $A_{2}$, group $X$ & $\underline{\text { Ile6 }}$ & -21.8 & -6.1 & [57] \\
\hline Octreotide -2 & $\underline{\text { Isoc }}$ & -5.6 & -5.4 & {$[155]$} \\
\hline Pancreatic lipase & lethA & -16.1 & -11.0 & {$[156]$} \\
\hline Cytotoxin I & $\underline{\operatorname{ltg} x}$ & -12.4 & -9.6 & {$[119]$} \\
\hline Sapecin & $\underline{\| 4 v}$ & -6.6 & -9.9 & {$[12 \mid]$} \\
\hline $\mathrm{Cl}$ domain of Raf-I kinase & $\underline{\mathrm{faq}}$ & -8.1 & -5.5 & {$[2]$} \\
\hline Gramicidin S & $\underline{\mathrm{Itk} 2}$ & -14.1 & -12.1 & {$[157]$} \\
\hline
\end{tabular}

Specific binding of lipid ligands (lipid clamps)

\begin{tabular}{|c|c|c|c|c|}
\hline $\mathrm{C} 2$ domain of $\mathrm{cPLA}{ }_{2}$ & $\underline{\text { Irlw }}$ & -7.1 & $-11.4 c$ & {$[84]$} \\
\hline $\mathrm{cPLA}_{2}$ holoenzyme & $\underline{\text { Icjy }}$ & -9.8 & -11.0 & {$[158]$} \\
\hline Phospholipase C $\delta I$ & $\underline{\text { Idjx}}$ & -3.2 & $-12.0^{b}$ & {$[159]$} \\
\hline C2 domain of synaptotagmin IA & lbyn & -4.4 & -6.5 & {$[160]$} \\
\hline$C 2$ domain of $P K C \beta$ & $\underline{\operatorname{la} 25}$ & -2.2 & -7.5 & {$[160]$} \\
\hline $\mathrm{C} 2$ domain of $\mathrm{PKC} \alpha$ & $\underline{\text { Idsy }}$ & -0.6 & $-12.8 c$ & {$[161]$} \\
\hline C2 domain of PTEN & $\underline{\mathrm{Id} 5 \mathrm{r}}$ & -2.6 & -9.7 & {$[162]$} \\
\hline $\mathrm{C} 2$ domain coagulation factor $\mathrm{Va}$ & $\underline{\text { Isdd }}$ & -5.6 & $-8.9 c$ & {$[163]$} \\
\hline C2 domain coagulation factor VIII & $\underline{I d 7 p}$ & -8.1 & -11.2 & [92] \\
\hline FYVE domain of $V_{p s} 27$ & $\underline{\text { Ivfy }}$ & -4.0 & -10.3 & {$[164]$} \\
\hline ENTH domain of epsin & $\underline{\text { Ih0a }}$ & -5.2 & -10.5 & [77] \\
\hline PX domain (p40phox) & $\underline{\ln 6 \mathrm{~h}}$ & -4.5 & -12.6 & [39] \\
\hline PX domain (p47phox) & $\underline{107 \mathrm{k}}$ & -2.7 & -12.1 & [39] \\
\hline $\mathrm{PH}$ domain of PLC- $\delta \mathrm{I}$ & $\underline{\text { mai }}$ & -3.2 & -6.2 & {$[165]$} \\
\hline Equinatoxin II & $\underline{\text { liaz }}$ & -2.2 & $-|I|$. & {$[166]$} \\
\hline
\end{tabular}

Predominantely nonspecific electrostatic binding

\begin{tabular}{lllll}
\hline Charybdotoxin & $\underline{2 c r d}$ & -1.6 & -3.6 & {$[17]$} \\
Mitochondrial cytochrome c & $\underline{\mathrm{hrc}}$ & -2.0 & -5.3 & {$[76,167]$} \\
\hline
\end{tabular}

Helix-coil transitions during binding

\begin{tabular}{|c|c|c|c|c|}
\hline Magainin & $2 \mathrm{mag}$ & -14.5 & -8.0 & {$[168]$} \\
\hline Alamethicin & $\underline{\text { lamt }}$ & -23.7 & -6.2 & [169] \\
\hline Zervamicin & $\underline{\operatorname{lih} 9}$ & -14.3 & -7.8 & [47] \\
\hline Neuropeptide $Y$ & licy & -9.4 & -4.7 & {$[125]$} \\
\hline
\end{tabular}

a Experimental values were taken for lipid compositions that provided maximal binding affinity and at the ionic strength close to physiological conditions $(\sim 0.1 \mathrm{M}$ of $\mathrm{KCl}) . \Delta G_{\text {exp }}$ values were taken from the original publications or calculated from the published molar partition coefficients of the proteins as $-\mathrm{RT} \ln \mathrm{K}_{d}$.

b Measured for isolated C2 domain of the protein.

c Different binding affinities were determined for these proteins in other studies $[8,160,170,171]$. 
However, the correlation does not hold for other groups of proteins (Figure 8). The energies were strongly underestimated for membrane targeting domains (PH, PX, FYVE, C2) and equinatoxin, which are known to associate specifically with certain types of lipids. Calculated energies of these lipid clamps differed by 5-9 kcal/mol from experimental energies measured in the presence of specifically bound lipids (Figure 8 ). This was expected, because the affinities of these proteins to membranes are weak in the absence of anchoring lipids. Thus, the omitted specific binding energy with headgroups of lipids $\left(\Delta G_{\text {spec }}\right)$ appeared to be predominant (up to $9 \mathrm{kcal} / \mathrm{mol}$ ) for these proteins.

Calculated energies were also underestimated for cytochrome $c$ and charybdotoxin whose binding is known to depend on electrostatic interactions (a part of the omitted $\Delta G_{\text {head-group }}$ term). However, the electrostatic energy was relatively small, $3 \mathrm{kcal} / \mathrm{mol}$ judging from the deviations in Figure 8 (all experimental data were taken for physiological concentrations of ions, usually $\sim 0.1 \mathrm{M} \mathrm{KCl}$ ).

In contrast, calculated energies were overestimated for peptides that undergo helix-coil transitions during their binding to the membrane, such as magainin and peptaibols. The energies were calculated for $\alpha$-helices that are found in crystals or in micelles, though such peptides are unfolded in aqueous solution. The energetic costs associated with folding of the $\alpha$-helices from coil can be significant, because they represent a combination of backbone energy (which is close to zero at $300 \mathrm{~K}$ ) and a sum of $\alpha$ helical propensities of all residues in the helix $[54,55]$. The propensities are positive (destabilizing) and vary from zero to $\sim 1 \mathrm{kcal} / \mathrm{mol}$ for individual residues, and up to 4 $\mathrm{kcal} / \mathrm{mol}$ for proline. Thus, $\Delta \mathrm{G}_{\text {conf }}$ may be large for peptides or proteins that undergo significant conformational changes during membrane binding, such as, lipases, or channel-forming toxins.

The calculated free energy was also strongly overestimated for phospholipase $\mathrm{A}_{2}$ from group $\mathrm{X}$ that has an unusually large exposed hydrophobic surface (1le6, not shown in Figure 8). It has been demonstrated that this protein easily associates with zwitterionic lipids at concentrations lower than critical micelle concentration [56]. Therefore, the experimental data [57] may reflect membrane binding affinity of a preexisting enzyme-lipid complex (that has a small exposed non-polar surface) rather than of a lipidfree enzyme.

This analysis shows that the most significant energetic contributions to binding energy for some proteins come from their transfer energy $\Delta G_{\text {trans }}$ specific binding of lipid ligands $\Delta G_{s p e c}$ (for lipid clamps), and changes of protein stability $\Delta G_{\text {conf }}$ (for peptides that undergo helix-coil transi- tions). Electrostatic interactions are less significant, although essential for binding of cationic proteins. Ionization energy is usually small because all ionizable groups of a typical peripheral protein remain outside the hydrophobic slab after energy minimization. The omitted membrane deformation energy, which depends on lipid composition, is also relatively small: it has been evaluated as $\sim 2-4 \mathrm{kcal} / \mathrm{mol}$ for $\alpha$-helical peptides [58]. Free energy of immobilization was estimated as only $~ 1 \mathrm{kcal} / \mathrm{mol}$ [27]. This explains the relatively small discrepancies in the energies for proteins from set (1) (Figure 8).

\section{Main categories of membrane-associated proteins}

After initial testing, the method was applied for identification and characterization of a wide spectrum of membrane-associated protein structures from the PDB. These structures were divided into three groups: (A) peripheral domains of integral transmembrane proteins; (B) integral monotopic proteins that are permanently membraneassociated; and (C) peripheral proteins that exist in free and membrane-bound states (see Table 5 and Additional file 1). Most of the selected proteins probably interact with lipid bilayers in vivo, as follows from UniProt and PubMed records, although some of them can only be tentatively assigned as membrane-associated. Membraneinteracting domains belong to 126 different superfamilies and 173 families based on SCOP classification [59]. Calculated transfer energies of these structures ranged from 2 to $-38 \mathrm{kcal} / \mathrm{mol}$, and membrane core penetration depths were between 1 to $15 \AA$ (Table 5). The results are less reliable and accurate for proteins with small transfer energies: the fluctuations of their penetration depths and tilt angles reached $3 \AA$ and $20^{\circ}$, respectively, within the energy interval of $1 \mathrm{kcal} / \mathrm{mol}$. These fluctuations are larger than for transmembrane proteins (up to $\pm 1.5 \AA$ and $\pm 5^{\circ}$, respectively, [26]).

Peripheral domains of transmembrane proteins (group "A") are usually water-soluble. However, some of them require detergents for extraction or crystallization, even after removal of their hydrophobic transmembrane $\alpha$-helices. Therefore, such domains are often described as integral monotopic [60]. Among them are monoamine oxidases $\mathrm{A}$ and $\mathrm{B}$, fatty acid amide hydrolase, mammalian cytochromes P450, corticosteroid dehydrogenases, and major envelope glycoprotein.

True integral monotopic proteins (group "B") do not have membrane-spanning $\alpha$-helices, by definition. Six integral monotopic proteins from the PDB include prostaglandin $\mathrm{H} 2$ synthases 1 and 2 ( $1 \mathrm{q} 4 \mathrm{~g}$ and $1 \mathrm{cx} 2$ ), lanosterol synthase (1w6k), squalene-hopene cyclase 2sqc), microsomal prostaglandin E synthase (1z9h), and carnitine O-palmitoyltransferase $2(2 \mathrm{~h} 4 \mathrm{t})$. 
Table 5: Typical membrane binding elements, calculated energies $\left(\Delta G_{\text {calc }}\right.$, kcal $\left./ \mathrm{mol}\right)$ and membrane penetration depths (D, $\AA$ ) for different categories of membrane-associated proteins (see Additional file I)

\begin{tabular}{|c|c|c|c|c|}
\hline Category & $\mathbf{N}^{\mathbf{a}}$ & Binding elements & $\Delta \mathbf{G}_{\text {calc }}(\mathrm{kcal} / \mathrm{mol})$ & $\mathbf{D}$ \\
\hline A. Extramembrane domains of transmembrane proteins & 29 & $\alpha$-helices, loops & -2.4 to -30.8 & 2.3 to 12.5 \\
\hline B. Integral monotopic & 6 & $\alpha$ helices, & -8.6 to -38.3 & 4 to 10 \\
\hline C.I. Peripheral enzymes & 119 & $\alpha$-helices, loops & -1.4 to -38.2 & I to 13 \\
\hline C.2. Water-soluble carriers of non-polar substances & 42 & $\alpha$-helices, loops, $\beta$-sheets & -2.2 to -20.7 & 2 to 8 \\
\hline C.3. Membrane-targeting and other structural domains & 93 & loops, $\alpha$-helices, bound lipids & -1.2 to -12.3 & I to 9 \\
\hline C.4. Electron carriers & 24 & Loops & -1.2 to -7.5 & I to 5 \\
\hline C.5. Polypeptide ligands (hormones, toxins, inhibitors) & 101 & $\beta$-sheets, $\alpha$-helices, loops & -1.6 to -18.1 & I to 18 \\
\hline C.6. Water-soluble forms of channel-forming polypeptides & 38 & $\alpha$-helices, loops & -1.3 to -20.9 & I to 28 \\
\hline
\end{tabular}

aNumber of different protein structures in the set.

All peripheral proteins (group "C") are water-soluble, a least in one of their conformational states [2]. These proteins usually reversibly associate with lipid bilayers. However, some polypeptide toxins can undergo conformational transitions and form transmembrane channels that are irreversibly associated with membranes, as in the case of $\alpha$-hemolysin. Some other water-soluble proteins may also adopt a transmembrane orientation during intermediate steps of their macromolecular assembly, as pilin IV, which forms the bacterial pilus [61], and the major coat proteins of filamentous phages. Such structures are not considered here but are included in OPM. Peripheral proteins were divided into six functional categories (C1-C6 in Table 5) that differ in typical membraneanchoring motifs, strength of hydrophobic interactions with lipid bilayers, and membrane penetration depth.

The first category (C.1.) includes 102 enzymes that participate in metabolism of different membrane components, such as lipids (e.g. phospholipases and cholesterol oxidases), cell wall oligosaccharides (e.g. glycosyltransferase and transglycosidases), or proteins (e.g. signal peptidase and palmitoyl protein thioesterases). They also process some hydrophobic substrates that can be dissolved in the membranes (e.g. substrates of carotenoid oxygenase) or exist as lipid micelles or non-polar droplets (e.g. substrates of pancreatic lipases). Calculated energies and penetration depths of many enzymes are relatively small either because the crystallized proteins were in the "closed state", less favorable for membrane binding (Table 6), or because some of their membrane-anchoring $\alpha$-helices or loops were disordered or missing in the crystal structures.

The second category (C.2.) includes 42 carriers that transfer small non-polar compounds between different types of cell membranes or between membranes and cytosolic protein complexes. The transported substances include phosphatidylinositol, $\alpha$-tocopherol, gangliosides, glycolipids, sterol derivatives, retinol and fatty acids.
The third category (C.3.) includes 85 membrane-targeting and other structural domains that mediate attachment of other proteins to membranes and may be involved in subcellular targeting and signal transduction [4,62]. These domains are usually attached to the membranes by the specific non-covalent binding of their cognate phospholipids (PE, PS, PIPs). However, non-specific hydrophobic and electrostatic interactions also play an important role. The interactions with lipids are also mediated by $\mathrm{Ca}^{2+}$ ions. Therefore, the presence of $\mathrm{Ca}^{2+}$ or specific phospholipids targets them to specific cellular compartments.

The fourth and fifth categories include 24 electron carriers (C.4.) and 88 different polypeptide ligands, i.e. hormones, toxins, inhibitors, or antimicrobial peptides (C.5). These proteins interact specifically with large transmembrane proteins. However, they may also be accumulated at the membrane surface prior to binding their protein targets. The carriers and polypeptide ligands are often positively charged and interact electrostatically with anionic membranes. The hydrophobic interactions of such proteins with membranes can vary from small to very significant.

The final category (C.6) includes 38 channel-forming polypeptides that undergo oligomerization and significant conformational transitions and thus may associate with membranes irreversibly. The structure of the membrane-bound state has been determined only for $\alpha$-hemolysin. In all other cases, the experimental structure represents a water-soluble conformation that only weakly binds to the lipid bilayer. It is noteworthy that such proteins are usually present as monomers in the crystals, although they form oligomers in membranes. Only alamethicin, mersacidin, tsushimycin, and one of $\delta$-endotoxins form dimers or trimers in crystals that might be biologically relevant.

\section{Discussion}

Orientations of many proteins in membranes have been experimentally studied (Tables 1 and 2), suggested from 
Table 6: Calculated parameters of open and closed states of membrane-associated proteins: binding energies $\left(\Delta \boldsymbol{G}_{\text {calc }}, \mathrm{kcal} / \mathrm{mol}\right)$, penetration depths $(D, \AA)$, and tilt angles $\left(\tau,{ }^{\circ}\right)$.

\begin{tabular}{|c|c|c|c|c|c|c|c|c|c|}
\hline \multirow[t]{2}{*}{ Protein } & \multirow[t]{2}{*}{ Category } & \multicolumn{4}{|c|}{ "Closed" state } & \multicolumn{4}{|c|}{ "Open"/lipid-bound state } \\
\hline & & PDB id & $\Delta \boldsymbol{G}_{\text {calc }}$ & $D$ & $\tau$ & PDB id & $\Delta \boldsymbol{G}_{\text {calc }}$ & $D$ & $\tau$ \\
\hline Cytochrome P450 2b4 & A.I & Isuo & -13.0 & 4.7 & 54 & $\underline{2 b d m}$ & -18.2 & 10.5 & 45 \\
\hline Fungal lipase I & C.I & Itrh & -7.8 & 3.0 & 80 & IIpp & -30.6 & 9.1 & 84 \\
\hline Triacylglycerol lipase Rhizomucor miehei & C.I & $\underline{3 \mathrm{tg} \mid}$ & -4.1 & 4.5 & 28 & $\underline{4 t g}$ & -14.0 & 4.9 & 55 \\
\hline Triacylglycerol lipase Humicola lanuginose & C.I & $\underline{\text { tib }}$ & -3.3 & 1.9 & 42 & lein & -13.5 & 9.5 & 71 \\
\hline Gastric lipase ${ }^{a}$ & C.I & $\overline{\mathrm{lhlg}}$ & -5.0 & 3.4 & 6 & $1 \mathrm{k} 8 \mathrm{q}$ & -10.8 & 6.3 & 80 \\
\hline$\alpha$-Toxin (Phospholipase C) & C.I & $\overrightarrow{\operatorname{lgyg}}$ & -4.2 & 5.5 & 60 & $\overrightarrow{|c a|}$ & -4.5 & 2.2 & 88 \\
\hline Alpha-tocopherol transfer protein & C.2 & $\underline{|r 5|}$ & -10.6 & 4.0 & 81 & $\underline{\text { loiz }}$ & -20.7 & 8.4 & 63 \\
\hline Glycolipid transfer protein & C.2 & $\underline{I s w x}$ & -4.9 & 3.4 & 86 & $\underline{1 s \times 6}$ & -7.9 & 3.9 & 87 \\
\hline Ganglioside GM2 activator & C.2 & $\underline{2 a g 4}$ & -5.1 & 4.2 & 47 & Itji & -9.3 & 4.6 & 55 \\
\hline Synaptotagmin C2A domain of $b$ & C. 4 & Irsy & -3.3 & 2.1 & 26 & $\underline{\text { lbynn }^{c}}$ & -4.4 & 3.7 & 36 \\
\hline Mersacidin & C.7 & $\operatorname{lmqx}^{c}$ & -2.3 & 2.4 & 77 & Imqy & -9.5 & 11.5 & 56 \\
\hline
\end{tabular}

a The open and closed forms of gastric lipase are taken from closely related species.

b $\mathrm{Ca}^{2+}$-free structure (I rsy) versus $\mathrm{Ca}^{2+}$-bound structure (Ibyn). $\mathrm{Ca}^{2+}$-bound state is usually referred as associated with the lipid bilayer.

c Structures determined by solution NMR spectroscopy. All other structures were solved by X-ray crystallography.

d "Closed" - structure in methanol solution, "open" - structure in DPC micelles. Crystal structure of the peptide (I qow) has intermediate values of $\Delta G_{\text {calc }}=-7.9 \mathrm{kcal} / \mathrm{mol}$ and $D=6.9 \mathrm{~A}$ (in the monomeric state).

their crystal structures (Table 3), or theoretically predicted (a few dozens of cases). However, the coordinates of proteins with membrane boundaries are publicly accessible only for a homology model of human pancreatic phospholipase $A_{2}$ ([11], Figure 5b) and several cardiotoxins available from authors upon request. Calculated spatial positions of other proteins in membranes can only be roughly estimated from the published pictures.

In the present work, we calculated the positions in membranes for more than 470 membrane-associated proteins and peptides, compared the results with available experimental data, and deposited all coordinates of proteins oriented in the lipid bilayer in our OPM database for easy public access [24]. At the present time, OPM is the only database that provides positions of peripheral and integral membrane proteins of known 3D structure in the lipid bilayer along with their structural classification, oligomeric states, topologies and subcellular localizations. Other bioinformatics resources focus only on transmembrane and a few integral monotopic proteins [63-65].

\section{Applicability of the method}

The large-scale computational analysis was accomplished using the hydrophobic slab model of the lipid bilayer implemented previously in our program PPM 1.0 [26]. In this model, protein-membrane association is driven by hydrophobic interactions that provide negative transfer energy. An opposite destabilizing contribution comes from the desolvation of polar and ionizable protein groups (equations (2-5)). Long-range Coulomb electrostatic interactions of the protein with headgroups of lipids were not included, because they strongly depend on specific lipid compositions of different biological membranes. This approach was previously verified only for transmembrane proteins, and for these systems was shown to be more consistent with experimental data [26] than other computational approaches, such as TMDET [63] or IMPALA [66].

Peripheral proteins represent a significant challenge for this method, because they have relatively small exposed non-polar regions and their hydrophobic interactions with lipid bilayers might be overridden by electrostatic or other interactions with headgroups of lipids, unless they work in concert with hydrophobic forces. In spite of potential complications, we found that PPM 1.0 performed surprisingly well, since the results were in close agreement with experimental data for the test set of 53 well-studied peripheral proteins and peptides (Tables 1, 2, 3 , Figures 1, 2, 3, 4, 5, 6, 7). The method was applicable due to the presence of exposed non-polar patches at the surfaces of all peripheral proteins in the dataset, which is sufficient for positioning of proteins in the lipid bilayer.

Our primary goal was to reproduce the spatial positions of proteins in membranes, rather than their binding affinities. However, the calculated transfer energies were fairly consistent with experimental binding energies for many peripheral proteins (Figure 8). The discrepancies of binding energies (but not the calculated orientations) have only been observed in special cases that involve specific lipid binding, helix-coil transitions, or predominantly electrostatic associations (Figure 8, Table 4). 
Due to its relative simplicity, our method can be applied to high-throughput screening of proteins with exposed non-polar patches that can potentially associate with membranes, unlike more complex and computationally expensive molecular dynamics simulations. The orientations obtained for numerous peripheral proteins from the PDB are in line with expectations of crystallographers (Table 3) and consistent with the arrangement of detergents, lipids, non-polar binding cavities, acylated residues and other structural features indicating which regions of the proteins are involved in membrane associations (see Results). Unfortunately, fully automated detection of membrane-associated proteins was not possible due to several limitations. First, many structures of peripheral proteins in the PDB are incomplete, because some or all of their anchoring elements are disordered or removed for crystallization. Second, some crystal or solution structures are different from the membrane-bound conformations of the corresponding protein. Third, it is often important to know a complete quaternary structure of a protein complex, rather than the structure of an individual polypeptide chain or a domain. Finally, it was essential to check the biological relevance of the detected protein-membrane association modes based on the literature and UniProt records, but such information is not always readily available or is difficult to interpret.

Apparently, our version of the continuum solvent approach can also be applied for positioning homology models of peripheral proteins in membranes, in addition to the experimental structures as in the present study. The method can be further improved by including free energy of helix-coil transitions for unfolded peptides $[55,67]$ and energetic contributions that are dependent on the lipid compositions of membranes, such as Coulomb electrostatic interactions, lateral pressure [53], and the hydrophobic mismatch [68].

\section{Importance of hydrophobic interactions with the bilayer core}

It is generally accepted that protein-membrane binding is driven by a combination of hydrophobic, electrostatic and other interactions (equation (1)). However, the model applied here includes only hydrophobic interactions, desolvation energy of polar groups, and ionization energy. This model was tested for two different datasets: (a) proteins whose spatial positions in the lipid bilayers or membrane binding affinities have been experimentally quantified in vitro and (b) a set identified from screening the PDB and subsequent analysis of results and relevant data and literature. The former set is not biased, since all appropriate examples were simply selected from the literature (see Methods). The latter set may be biased toward proteins that are more amendable to our method. However, this second set was extremely diverse. It included 6 integral monotopic, 415 peripheral proteins, and 55 membrane-associated peptides from the $\mathrm{PDB}$, which were classified into seven functional categories: enzymes, structural and regulatory domains, membrane-targeting domains (lipid clamps), transporters of hydrophobic substances, electron carriers, polypeptide ligands (hormones, inhibitors, toxins, and antimicrobial peptides), and channel-forming polypeptides (Table 5).

The ability of the method to accurately predict the positions and orientations of hundreds of peripheral proteins indicates the importance of hydrophobic interactions for protein-membrane association. All these proteins, including lipid clamps, have some surface non-polar residues that associate with the bilayer core. These residues were sufficient for defining a unique spatial position of the proteins even in the cases in which the binding is driven by specific protein-lipid interactions.

The important role of hydrophobic interactions is expected. Peripheral proteins are known to associate with lipid bilayers through various hydrophobic anchors, such as amphiphilic $\alpha$-helixes, exposed non-polar loops, or acylated amino acid residues [2]. Hydrophobic interactions of non-polar or acylated residues are essential even for highly cationic peptides and proteins of natural origin, such as the polybasic domain of MARCKS protein or the $\mathrm{pH}$ sensor hisactophilin $[18,69]$. It has been shown that even unfolded peptides may penetrate through the lipid headgroup region and reach the hydrocarbon interior of the membrane if they have a few non-polar residues [70$72]$, similar to amphiphilic $\alpha$-helical peptides $[73,74]$.

A variety of typical membrane-anchoring structures was found during our computational analysis of the large set of diverse proteins. For example, amphiphilic $\alpha$-helices serve as membrane anchors in all integral monotopic proteins, in a majority of membrane-associated enzymes, and in many channel-forming peptides (Table 5). On the other hand, snake venom toxins, defensins, and some antimicrobial peptides may interact with membranes through amphiphilic $\beta$-hairpins, $\beta$-sheets or $\beta$-turns. However, an exposed hydrophobic loop likely represents the most common structural element that may either interact with the membrane interface or penetrate into the hydrophobic region. A typical membrane-bound hydrophobic loop looks like an elongated protrusion that penetrates through the interfacial regions of the lipid bilayer. Such protrusions usually present some exposed hydrophobic (often aromatic) residues at their tips, flanked by basic and aromatic residues (Lys, Arg, Tyr, Trp) that interact favorably with headgroups of lipids [75]. The irregular shape of membrane-binding loops facilitates the creation of binding cavities for lipids that specifically interact with 
headgroups of lipids, such as annexins or anemone cytolysins.

The hydrophobic interactions are not necessarily predominant. Another very important and common mechanism is the specific non-covalent binding of regulatory lipids, as has been found for membrane-targeting domains [4]. Non-specific electrostatic interactions are also present and may be important for targeting of the proteins to their destination membranes. Electrostatic interactions are relatively weak at physiological ionic strength. They account for 3 to $4 \mathrm{kcal} / \mathrm{mol}$ for small cationic proteins, such as cytochrome c, charybdotoxin (Figure 8), or hisactophilin $[17,67,76]$, interacting with negatively charged membranes. It is noteworthy that such interactions are proba-

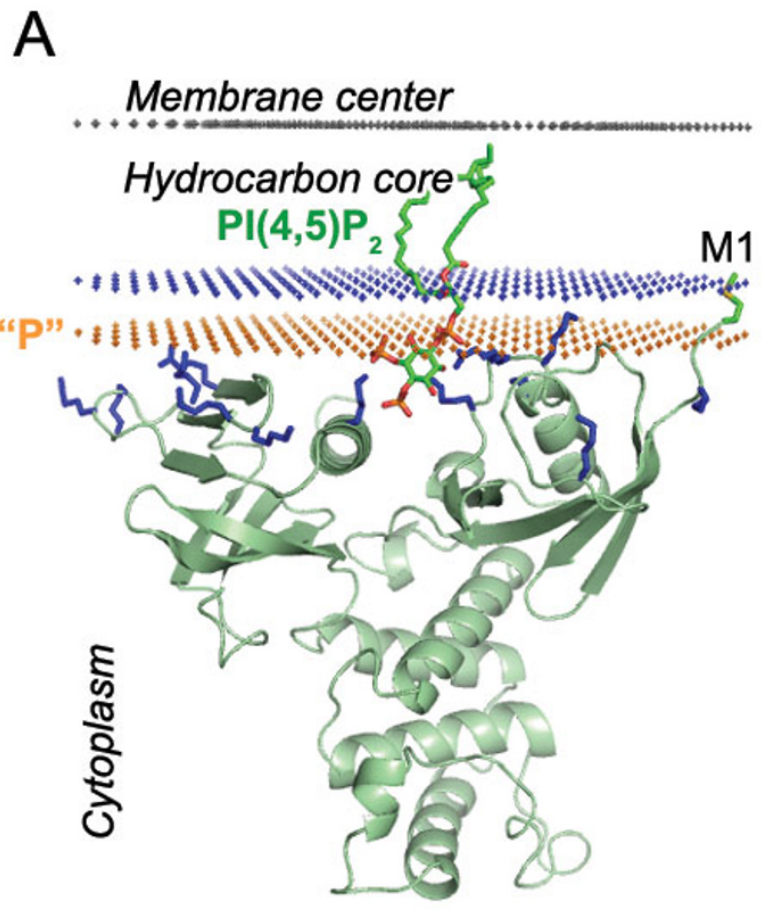

\section{Radixin-FERM (1gc6)}

bly not long-range, but rather involve formation of ion pairs, especially between clusters of basic residues and phosphoinositides (Figures 1B and 9).

The results of our calculations are consistent with classification of peripheral proteins as H, I, and S-types [4]. Htype proteins and peptides have many exposed non-polar residues that penetrate into the hydrocarbon core region. They include integral monotopic domains, amphiphatic antibacterial peptides, lipopeptide antibiotics (e.g. daptomycin), some polypeptide toxins, water-soluble transporters of small non-polar molecules, such enzymes as phospholipases and lipoxygenases, and probably several membrane-targeting domains $\left(\mathrm{CPLA}_{2}-\mathrm{C} 2, \mathrm{PKC} \delta-\mathrm{C} 1 \mathrm{~B}\right.$, Epsin-ENTH).

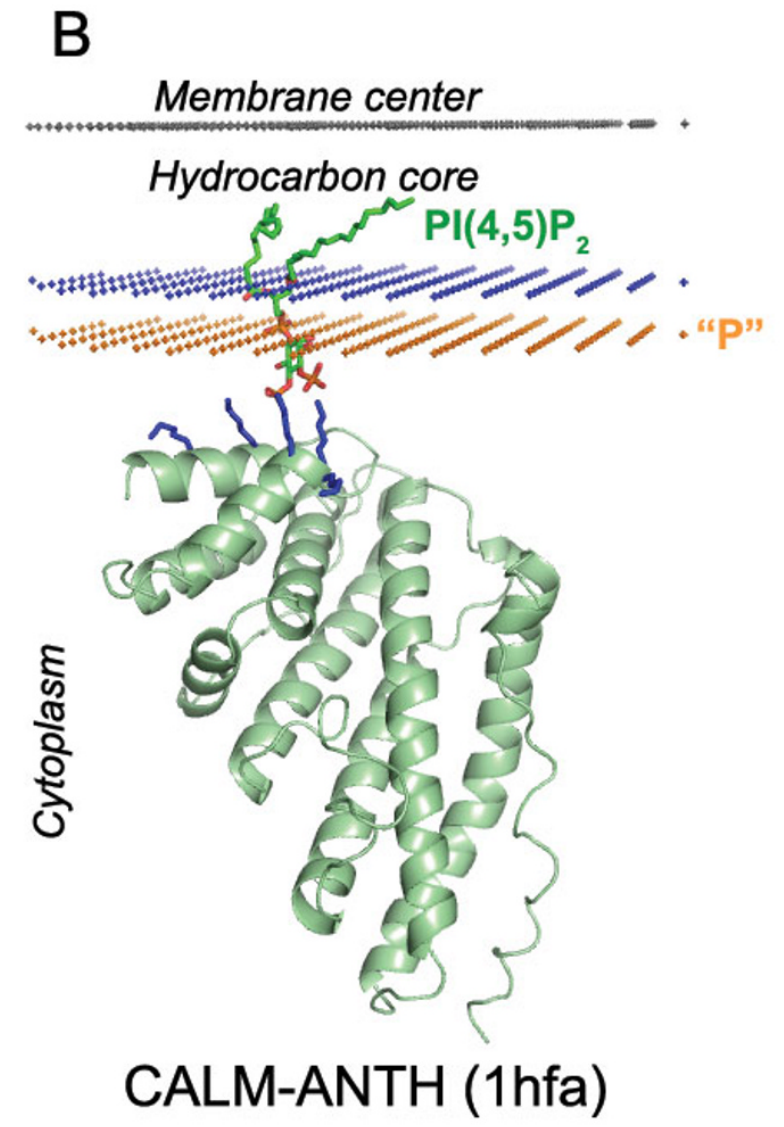

\section{Figure 9}

Calculated membrane binding modes for Radixin-FERM domains with lipid ligand $P I(4,5) P_{2}(A)$ and $C A L M-$

ANTH with lipid ligand $\mathbf{P I}(\mathbf{4 , 5}) \mathbf{P}_{\mathbf{2}} \mathbf{( B )}$. The backbone of two S-type domains and the specific lipid ligands are shown in ribbon and stick model, respectively. Cationic residues involved in ligand and membrane interactions are colored blue. Hydrocarbon core boundary at the cytoplasmic side is indicated by blue dots. The layer of lipid phosphates ("P") is shown by gold dots (at $5 \AA$ outside the hydrocarbon boundary). The center of membrane is indicated by grey dots (at I5 $\AA$ inside the boundary). 
I-type proteins have fewer exposed non-polar residues. They may only contact with the hydrocarbon core by their non-polar residues but stay primarily in the membrane interfacial region. A majority of membrane-targeting domains, such as $\mathrm{C} 2, \mathrm{PX}$ and $\mathrm{PH}$, discoidin domains (Figures $1,2,3$ ) and annexins, belong to this category.

S-type ("surface") proteins are usually cationic, have only one or two exposed non-polar residues, and bind their anchoring lipids with relatively low affinity and specificity. Association of S-proteins with membranes strongly depends on the ionic strength [77]. These proteins are usually described as involved in long-range electrostatic interactions with the membrane surface, while remaining in the aqueous solution [17]. However, according to our results, Lys and Arg residues of these proteins may penetrate into the interfacial region and form ionic pairs with lipid phosphate groups (as in radixin-FERM, Figure 9A). Moreover, even proteins that are located at the membrane surface (as CALM-ANTH in Figure 9B) may also form direct ionic bridges with $\mathrm{P} 4$ and $\mathrm{P} 5$ of phosphoinositides in addition to the long-range electrostatic interactions with the membrane surface. Such protein-lipid ionic bridges may be weakened at high ionic strength [77], just as ionic pairs in peptides [78].

\section{Conformational changes during protein-membrane association}

Typical peripheral proteins are prone to conformational changes in response to phosphorylation or binding of ions, ligands, or other proteins [5]. Structural changes range from rearrangements of side chains and loops to refolding and significant movements of regular secondary structures. Such changes may promote the protein binding to the membrane, which in turn stabilizes the membrane-bound conformation [2]. Some examples of conformational rearrangements are shown in Tables 6 and 7 .

The majority of experimental structures represent the "closed" state, which is more stable in aqueous solution. Relatively few structures represent an "open" state that is more favorable in membranes (Table 6). During crystallization, "open" states can be stabilized by lipids (lipases, glycolipid transfer protein, or ganglioside GM activator), detergents ( $\alpha$-tocopherol transfer protein), micelles (mersacidin), $\mathrm{pH}$ changes ( $\alpha$-toxin), $\mathrm{Ca}^{2+}$ ions (C2A domain of synaptotagmin), or by formation of presumably nonnative dimers (one of cytochromes P450).

According to our results, calculated energies of proteins in the "open states" are usually lower than in the "closed states" (Table 6). Thus, "open" conformations are more prone to membrane association. Further, the "open" conformation also penetrates deeper into the membrane. Predicted membrane binding regions are overlapped in the different states of the proteins, although they may slightly differ. The initial weak association of the "closed" state to the membrane facilitates its subsequent transformation to the "open" (productive) state. On the other hand, the conformational change from the "open" to the "closed" state may be required for dissociation of the protein from the membrane.

There are also many cases in which the alternative structural states are not defined as "closed" and "open", although they have different conformations of membrane-interacting loops due to ligand binding, different crystallization conditions, or cleavage of different segments of the polypeptide chain. The calculated spatial positions of such conformational states in the membrane can also be somewhat variable (Table 7).

Table 7: Comparison of calculated energies $\left(\Delta G_{\text {calc }}, \mathrm{kcal} / \mathrm{mol}\right)$, predicted penetration depths $(D, \AA)$ and protein tilts with respect to the membrane normal $\left(\tau,{ }^{\circ}\right)$ for alternative conformations of membrane-associated loops of different peripheral proteins.

\begin{tabular}{|c|c|c|c|c|c|c|c|c|c|}
\hline \multirow[t]{2}{*}{ Protein } & \multirow[t]{2}{*}{ Category } & \multicolumn{4}{|c|}{ Conformation Ia } & \multicolumn{4}{|c|}{ Conformation $2^{a}$} \\
\hline & & PDB id & $\Delta \boldsymbol{G}_{\text {calc }}$ & D & $\tau$ & PDB id & $\Delta \boldsymbol{G}_{\text {calc }}$ & $D$ & $\tau$ \\
\hline Signal peptidase & A.I & $\underline{1 \mathrm{kn} 9}$ & -4.5 & 4.5 & 83 & $\underline{\mid t 7 d}$ & -5.9 & 3.7 & 66 \\
\hline Cytochrome P450 2b4 & A.I & $\overline{1 p 05}$ & -6.9 & 9.7 & 39 & $\overline{2 \mathrm{bdm}}$ & -18.2 & 10.5 & 45 \\
\hline Cytochrome P450 2c5 & A.I & Inr6 & -11.6 & 12.5 & 54 & $\underline{I d t 6}$ & -8.4 & 7.5 & 17 \\
\hline Cytochrome P450 2c9 & A.I & $\underline{\log 5}$ & -13.6 & 7.5 & 74 & $\overline{\operatorname{lr} 90}$ & -10.7 & 7.5 & 57 \\
\hline Cytochrome P450 3a4 & A.I & $\operatorname{tgn}$ & -20.7 & 10.2 & 61 & IwOf & -15.2 & 6.2 & 68 \\
\hline Bile-salt activated lipase & C.I & $\underline{|a q|}$ & -9.7 & 6.0 & 80 & $\underline{\text { lakn }}$ & -6.6 & 5.7 & 67 \\
\hline Triacylglycerol lipase & C.I & $\underline{\text { tib }}$ & -3.3 & 1.9 & 42 & $\underline{1 \mathrm{dt} 5}$ & -4.8 & 2.9 & 84 \\
\hline Lipase/colipase complex & C.I & Ilpa & -22.1 & 8.7 & 89 & $11 p b$ & -26.2 & 10.3 & 87 \\
\hline Ganglioside GM2 activator & C.2 & t tii & -9.3 & 4.6 & 55 & $\underline{\text { Ipub }}$ & -7.8 & 5.2 & 44 \\
\hline Phosducin/ $\beta \gamma$ complex & C.3 & $\mathrm{IaOr}$ & -3.7 & 2.7 & 45 & $\underline{2 \mathrm{trc}}$ & -2.9 & 4.4 & 64 \\
\hline Tubby protein & C. 4 & $\underline{1 c 8 z}$ & -4.2 & 6.2 & 87 & $\underline{\text { li7e }}$ & -3.6 & 2.6 & 78 \\
\hline
\end{tabular}

a All structures were solved by X-ray crystallography. 


\section{Comparison with other computational methods}

The positions of proteins in membranes can be simulated using three different computational approaches: (a) energy minimization using the hydrophobic slab approximation of the lipid bilayer (as in the present study), (b) molecular dynamics (MD) simulations with explicit lipids, or (c) optimization of Coulomb electrostatic interaction energy of the protein with a charged planar membrane surface.

The first approach was applied here. It implements the implicit solvent approximation, which is based on the experimental linear relationship between the transfer energy and the accessible surface areas of solutes [79]. The required atomic solvation parameters have been derived from water-decadiene partition coefficients of organic molecules [27]. This method has a significant advantage: it operates directly with free energy of solvation, unlike molecular mechanics or electrostatic methods that include only the enthalpic component of free energy. Several versions of the implicit solvation model have been applied for positioning of $\alpha$-helical peptides and transmembrane proteins in membranes [16]. However, this method has rarely been applied to peripheral proteins. Most notably, orientations of several snake venom cardiotoxins in the lipid bilayer have been simulated by Monte Carlo optimization with atomic solvation parameters that are different from ours. Coordinates of these cardotoxins were kindly provided by the authors [16], and thus can be compared with our results. This method is more computationally expensive because it refines the experimental $3 \mathrm{D}$ structures of the proteins, instead of keeping the initial structure, as in the present work. The simulated orientations of these toxins are similar to those in the present study (Figure 10). In particular, sets of membrane-penetrating residues are almost identical. A significant deviation in the tilt $\left(\sim 25^{\circ}\right)$ was observed only for the cobra cardiotoxin CTXI (2cdx). This deviation may be caused by different conformations of the membrane-interacting loops in the original NMR model (used in this work), as compared with the conformation of the membraneembedded neurotoxin obtained after its energetic refinement [16]; $2.7 \AA$ År.m.s.d. of all C $\mathrm{C}^{\alpha}$ atoms).

The results of MD simulations with explicit water and lipids are also very similar to our results. For example, the orientations and membrane penetration depths of ovine prostaglandin $\mathrm{H} 2$ synthase 1 [12] and human secreted phospholipase $A_{2}$ [13] obtained by MD simulations are close to those obtained by our method (OPM entries $1 \mathrm{q} 4 \mathrm{~g}$ and 1n28, Figure 6B). However, this comparison was based only on the published pictures of these proteins in membranes, because the MD-simulated coordinates of the proteins with lipids are unavailable.
The membrane-interaction regions of the proteins calculated by the electrostatic method were also rather similar to our results for three FYVE domains [21], the PH domain of phospholipase C [20], C2 domains [19], and phospholipase $\mathrm{A}_{2}$ [22]. This indicates that hydrophobic and electrostatic forces may actually work in concert to provide a stronger protein-membrane association. However, membrane penetration depths calculated by the electrostatic method were different by 10-15 $\AA$ from the results obtained by all other methods, including MD [13], Monte Carlo simulations [16], and this work.

The electrostatic approach minimizes electrostatic energy of a protein at the charged planar membrane surface based on the finite difference Poisson-Boltzmann method [17-21]. This model omits hydrophobic interactions with the bilayer core and specific interactions with headgroups of lipids. Thus, it only includes a part of the $\Delta G_{\text {head-group }}$ contribution in equation (1). It is assumed that the protein does not penetrate through the continuous van der Waals surface formed by headgroups of the lipids (although a few atoms can be artificially removed to allow some penetration into the interfacial rather than acyl chain region [22]). Therefore, in the electrostatic model, all proteins are located $\sim 2 \AA$ above the membrane surface. However, other computational methods demonstrate that these proteins pass through the interfacial region and penetrate the hydrophobic core by 1 to $6 \AA$, consistent with numerous experimental studies (EPR, fluorescence and others), positions of co-crystallized detergents, lipids, and $\mathrm{Ca}^{2+}$ ions, and location of charged residues important for the protein binding inside the interfacial region (see Results).

\section{Conclusion}

Our computational method for the positioning of proteins in membranes was successful for the set of 53 wellstudied peripheral proteins. Therefore it was applied for the calculation of more than 470 membrane-associated proteins and peptides from the PDB. Here, for the first time, we have collected all peripheral proteins with known structures whose orientations have been experimentally studied in vitro and analyzed and classified a large and diverse set of peripheral proteins from the PDB. All these protein structures with calculated membrane boundaries are available through the OPM database.

Our calculations demonstrate the key role of non-specific hydrophobic and specific interactions with the lipids in the binding and arrangement of peripheral proteins in membranes. We find that most proteins examined not only interact with the membrane surface, but penetrate through the interfacial region and participate in the hydrophobic interactions with the hydrocarbon interior of membranes. This relatively deep penetration of periph- 

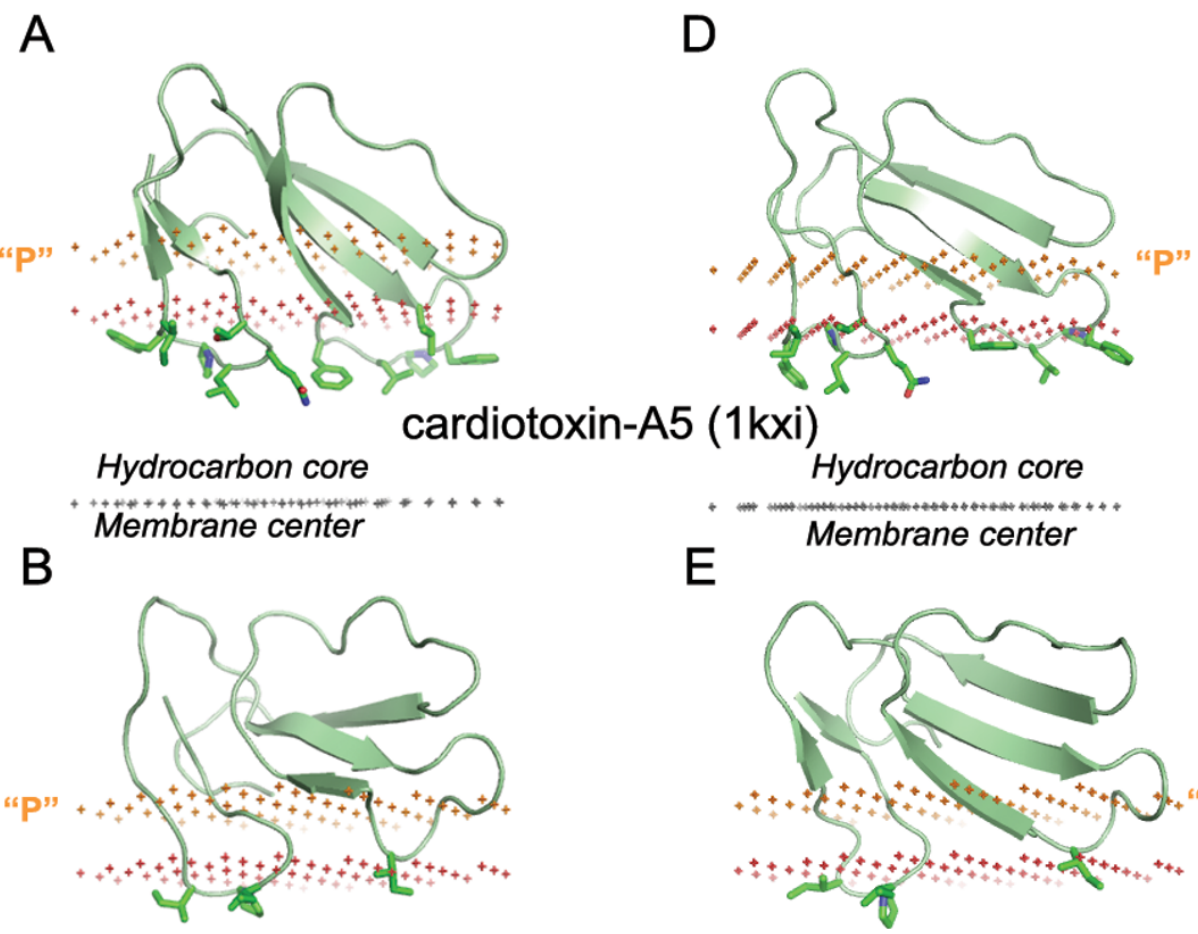

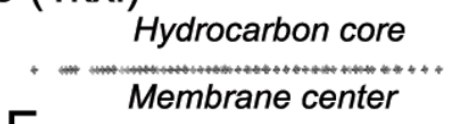

$E$

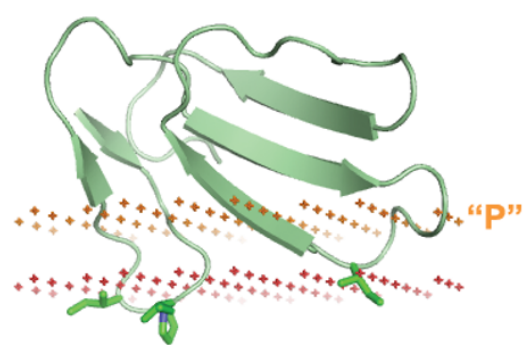

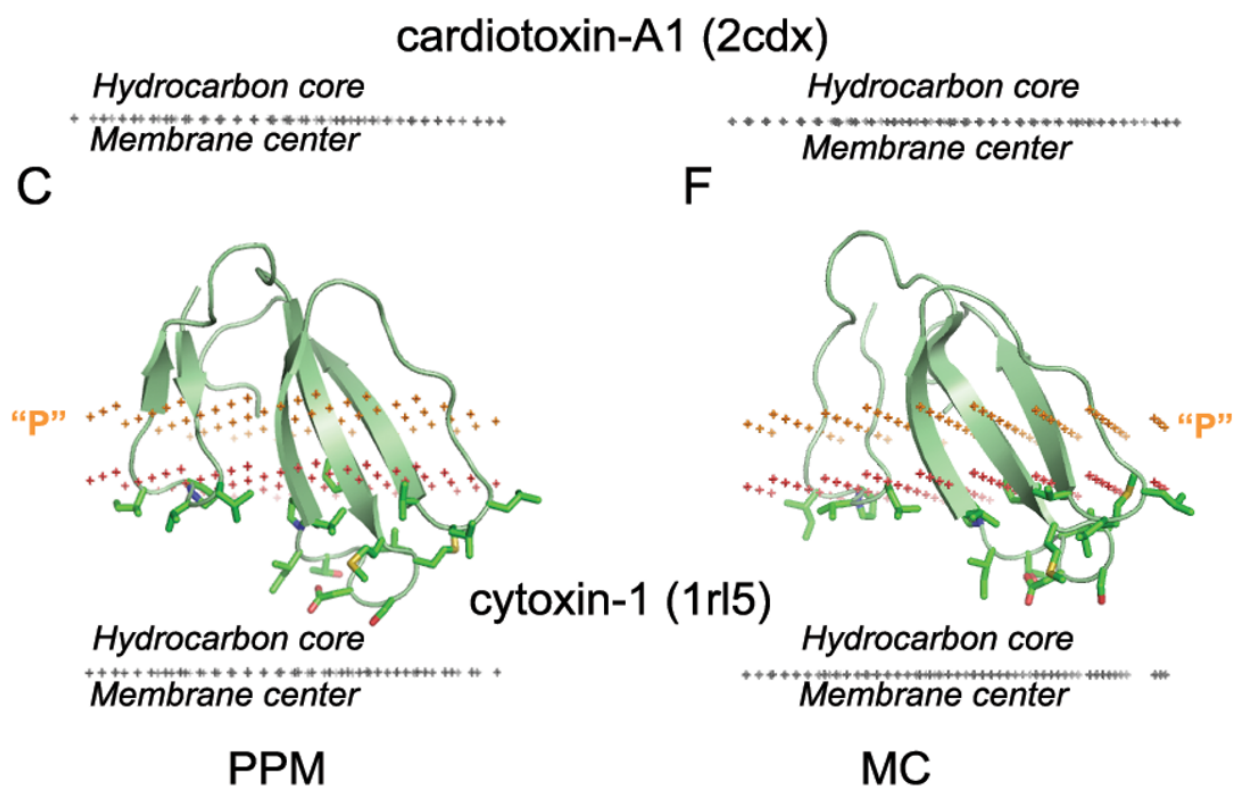

Figure 10

Comparison of positions in the lipid bilayer of homologous toxins calculated by different methods. Cardiotoxin A5 (A, D), cardiotoxin AI (B, E) and cytoxin I (C, F) were calculated byPPM (A-C) or by Monte Carlo Simulations (D-F) in the hydrophobicslab. Coordinate sets of the toxins were kindly provided by Dr. Efremov [16]. The backbone of toxins is shown in ribbon model. Hydrocarbon core-penetrating residues are shown in stick model. Hydrocarbon core boundary at the extracellular side is indicated by red dots. The layer of lipid phosphates ("P") is shown by gold dots (at $5 \AA$ outside the hydrocarbon boundary). The center of membrane is indicated by grey dots (at I5 $\AA$ inside the boundary). The orientations of each protein obtained by PPM and MC simulations are rather similar; and sets of membrane-penetrating residues are identical. However, the tilt between the protein axis and the membrane normal differ by $3^{\circ}$ for $\mathrm{Irl} 3$, by $10^{\circ}$ for $\mathrm{lkxi}$ and by $25^{\circ}$ for $2 \mathrm{cdx}$. 
eral proteins is consistent with experimental studies by spin-labeling, fluorescence, and NMR spectroscopy, significant contributions of exposed non-polar residues to membrane binding affinities as evaluated by mutagenesis, locations of crystallized lipids in the protein structures, and results of independent calculations with the hydrophobic slab model and MD simulations with explicit lipids.

\section{Methods}

\section{Energy optimization}

The computational approach for positioning of membrane proteins was previously descibed and implemented in program PPM 1.0. [26]. A protein was considered as a rigid body freely floating in the fluid hydrocarbon core of a lipid bilayer. Free energy of the protein $\left(\Delta G_{\text {calc }}\right)$ represented a sum of transfer energies of all its atoms from water to the hydrocarbon core of the lipid bialyer $\left(\Delta G_{\text {transf }}\right)$ and the ionization energies of charged residues $\left(\Delta G_{p K}\right)$ :

$$
\Delta G_{\text {calc }}(\varphi, \tau, d)=\Delta G_{\text {transf }}+\Delta G_{p K}
$$

The free energy difference was optimized in a coordinate system, in which $\mathrm{Z}$ axis is normal to the bilayer, and the origin is the bilayer center. This free energy difference depends on three variables $(\varphi, \tau, d)$; where $d$ is the shift of the protein center along the $\mathrm{Z}$ axis relative to the xy plane, $\tau$ is the tilt angle of the longitudinal protein axis relative to the $\mathrm{Z}$ axis (membrane normal), and $\varphi$ is the rotation angle that defines the direction of the tilt. The tilt $(\tau)$ of peripheral proteins was calculated as the angle between the bilayer normal and the molecular axis, relative to which the protein has the minimal moment of inertia [10]. This is different from the definition of longitudinal axis in transmembrane $\alpha$-bundles and $\beta$-barrels as vector averages of transmembrane secondary structure vectors [26].

The energy of protein transfer from water to the lipid bilayer was calculated using the implicit solvation model:

$$
\Delta G_{\text {transf }}=\sum_{i} A S A_{i} \sigma_{i}^{W-M} f\left(z_{i}\right)
$$

where $A S A_{i}$ is the accessible surface area of atom $i$, and $\sigma_{i}^{W-}$ $M$ is the solvation parameter of atom $i$ (its transfer energy from water to membrane interior expressed in $\mathrm{kcal} / \mathrm{mol}$ per $\AA^{2}$ ). ASA were determined using the subroutine SOLVA from NACCESS (provided by Dr. Hubbard) with van der Waals radii from Chothia [80], which implicitly take into account hydrogen atoms, and with the solvent probe radius of $1.4 \AA$.

All atomic solvation parameters were derived from the partition coefficients of organic compounds between water and decadiene [27]. These parameters were normalized by the effective concentration of water, which changes gradually in a narrow region between the lipid headgroup region and the hydrocarbon core. We used a sigmoid water concentration profile $f\left(z_{i}\right)$, as determined in EPR studies on spin-labeled phospholipids [25,81]:

$$
f\left(z_{i}\right)=1 /\left(1+e^{\left(\left|z_{i}\right|-z_{0}\right) / \lambda}\right)
$$

The characteristic distance $\lambda$ of this profile was chosen as $0.9 \AA$ [ [25].

All charged residues of the protein were considered neutral in the membrane hydrocarbon core. The corresponding ionization energy was described by the HendersonHallelbalch equation, where the ionization energy of each residue $k$ was distributed between its charged side-chain $\mathrm{O}$ or $\mathrm{N}$ atoms proportional to their relative accessible surface areas $A S A_{i}$ :

$$
\Delta G_{p K}=2.3 R T \sum_{k=1}^{N}\left[\left(p H-p K_{k}\right) \sum_{i=1}^{M_{i}}\left(A S A_{i} / A S A_{k}^{t o t}\right) f\left(z_{i}\right)\right]
$$

where $A S A_{k}$ tot is the total $A S A$ of all charged atoms in the residue. pKa values of aspartate, glutamate, lysine, and aspargine residues were chosen as described previously [26]. The corresponding $\Delta G_{p K}$ value for a histidine was zero, and the values for other residues were from 4 to 7 $\mathrm{kcal} / \mathrm{mol}$. Based on equation 5, the contributions of solvent-inaccessible charged groups were zero (such groups do not change their ionization state in the membrane). An ionizable group was treated as solvent-inaccessible if ASA of its polar atoms was less than $1 \AA$, or if it formed at least two hydrogen bonds in the protein structure.

Global energy minimization was performed by combining a grid scan and the Davidon-Fletcher-Powell method [26]. The lowest energy arrangement was always selected. Conformers of selected flexible side-chains located close to the water-membrane interface were adjusted as described previously [26]. Ligands were included only for membrane targeting domains co-crystallized with their lipid head group analogues (e.g. 1bwn, 1joc, or $1 \mathrm{dsy}$ ). Then, acyl chains of bound lipids were reconstructed. A conformational search was conducted for five torsion angles in the lipid headgroup region (starting from P1-C2 bond) to identify conformers $\left( \pm 60\right.$ or $180^{\circ}$ ) which do not produce interatomic hindrances and provide the lowest calculated transfer energies for each protein. The modeling was accomplished using QUANTA. 


\section{Selection of well studied peripheral proteins}

The set of peripheral proteins used for validation of our computational approach included all proteins with known 3D structures whose orientations in the lipid bilayer (53 proteins in Tables 1 and 2) or membrane binding affinities (38 proteins in Table 4) were experimentally evaluated in vitro, excluding studies conducted at nonphysiologically low ionic strength. The selection was based on the following criteria: (1) 3D structures of the proteins represented the same domain or a combination of domains that were used in the binding studies, (2) potential membrane-interacting regions were present (not disordered or missing) in the crystal or NMR structures; (3) no significant conformational transitions or aggregation was experimentally detected during binding of the protein with lipid bilayers.

\section{Selection and analysis of membrane-associated proteins from the PDB}

Identification and analysis of peripheral proteins from the PDB included the following six steps. First, all structures from the PDBSELECT90 set $(\sim 11,500$ structures in release of November 2005, excluding viral particles) were optimized by our program PPM 1.0. A set of $\sim 70$ peptides was added, because PDBSELECT contains only polypeptide chains longer than 30 residues. Oligomeric structures were generated by Protein Quaternary Structure (PQS) server [82].

Secondly, all structures with calculated energies $\left(\Delta G_{\text {calc }}\right)$ lower than $-1 \mathrm{kcal} / \mathrm{mol}$ were selected and visually analyzed to eliminate proteins whose hydrophobic regions represented disordered loops with undefined spatial positions (usually in NMR models, at the N- or C-termini, or near regions with missing electron density).

Third, the remaining 2700 structures were classified automatically to different SCOP families [59] based on the architecture of their largest membrane-associated domain.

Fourth, families whose proteins either had low transfer energies or potentially interacted with membranes (based on keyword search of PDB and SwissProt) were selected. The potential membrane-interacting regions were compared for all proteins in each family to define whether these regions represented the same or alternative binding modes in related proteins (alternative binding sites were detected in a relatively small number of cases, such as PX domains or small G-proteins).

Fifth, a quick analysis of UniProt and related PubMed records was conducted to define which structures could indeed associate with membranes, and retrieve their primary subcellular localization and topology. It was impor- tant to check if the obtained hydrophobic regions are known to be involved in association with other proteins in vivo, rather than interactions with lipid bilayers. For example, the "switch regions" of G-proteins, poly-Pro sequences in vinculin, and hydrophobic sites of extracellular domain of bone morphogenetic receptor are established protein-protein recognition motifs. All proteins with such regions were eliminated, except when these regions may be of "dual purpose", i.e. interact with bilayers as well as with other proteins in vivo (some toxins, polypeptide hormones, etc.). Finally, different PDB entries representing each selected protein were superimposed by the Secondary Structure Matching (SSM) server [83] to identify all significantly different structures, such as open and closed states of lipases. Also, the most functionally relevant quaternary structure of each complex was selected. This was usually the largest oligomeric complex (as defined by the PQS server), unless some data suggested otherwise. For instance, all phospholipases $\mathrm{A}_{2}$ and cytochromes P450 were taken as monomers, although some of them form dimers or trimers in crystals. Such oligomers may be stable in the crystal or even in aqueous solution, but they presumably dissociate in the membrane.

3D structures of identified peripheral proteins and membrane-associated peptides with calculated hydrophobic boundaries were deposited in the OPM database $[1,24]$, with their calculated tilt angles, maximal membrane penetration depths, transfer energies, locations of hydrocarbon boundaries, spatial positions of all atoms in the membrane coordinate system, subcellular localization, topology, structural classification, and experimental verification data with PubMed references.

\section{Abbreviations}

OPM, Orientations of Proteins in Membranes database; PPM, Positioning of Proteins in Membranes, (software); PDB, Protein Data Bank; SCOP, Structural Classification of Proteins database; SDSL, site-directed spin-labeling; PKC-C1, protein kinase $\mathrm{C}$ conserved 1; PKC-C2, protein kinase $\mathrm{C}$ conserved 2; $\mathrm{PH}$, pleckstrin homology; EEA1FYVE, Fab1, YOTB, Vac1 and Early endosomal antigen 1, PX, phox; ENTH, Epsin N-terminal Homology; ANTH, AP180 N-terminal Homology; FERM, Band 4.1, Ezrin, Radixun, Moesin; $\mathrm{CPLA}_{2}$; cytosolic phospholipase $\mathrm{A}_{2}$; sPLA $_{2}$, secreted phospholipase $\mathrm{A}_{2}$; sytI, synaptagmin I; PI, phosphatydylinositol, PS, phosphatidylserine, PC, phoshatidylcholine; PE, phosphatidylethanolamine; PMA, phorbol 12-myristate 13-acetate; $\mathrm{PI}(4,5) \mathrm{P}_{2}$, phosphatidylinositol-4,5-diphosphate; $\mathrm{PI}(3,4) \mathrm{P}_{2}$, phosphatidylinositol-3,4-diphosphate; PI(3)P, phosphatidylinositol-3-monophosphate; PI(4)P, phosphatidylinositol-4-monophosphate. 


\section{Authors' contributions}

ALL developed the method and software, calculated the positions of proteins in membranes, analyzed the results, and maintained OPM database; IDP participated in analysis and interpretation of results, compared them with published experimental studies, and created figures, MAL developed and maintained the OPM database. All authors participated in the manuscript preparation and approved the final manuscript. Authors declare that they have no competing interest.

\section{Additional material}

\section{Additional file 1}

A Table. Calculated membrane penetration depths $(\mathrm{D}, \AA)$ and binding energies $\left(\Delta \mathrm{G}_{\mathrm{calc}}, \mathrm{kcal} / \mathrm{mol}\right)$ of selected monotopic and peripheral proteins included in the OPM database.

Click here for file

[http://www.biomedcentral.com/content/supplementary/14726807-7-44-S1.doc]

\section{Acknowledgements}

We are grateful to Dr. Oleg Tsodikov for critically reading the manuscript and to Dr. Roman Efremov for the provided coordinates of cardiotoxins in a lipid bilayer. This work was supported by NIH grant DA003910 (HIM) and an Upjohn Research Award from the College of Pharmacy, University of Michigan (ALL, IDP).

\section{References}

I. Orientations of Proteins in Membranes (OPM) database [http://opm.phar.umich.edu]

2. Johnson JE, Cornell RB: Amphitropic proteins: regulation by reversible membrane interactions. Mol Membr Biol 1999, 16:217-235.

3. Goni FM: Non-permanent proteins in membranes: when proteins come as visitors. Mol Membr Biol 2002, 19:237-245.

4. Cho W, Stahelin RV: Membrane-protein interactions in cell signaling and membrane trafficking. Annu Rev Biophys Biomol Struct 2005, 34:||9-|5|.

5. Seaton BA, Roberts MF: Peripheral membrane proteins. In Biological Membranes Edited by: Mertz K, Roux B. Boston Birkhauser; 1996:355-403.

6. Frazier AA, Wisner MA, Malmberg NJ, Victor KG, Fanucci GE, Nalefski EA, Falke J], Cafiso DS: Membrane orientation and position of the C2 domain from cPLA2 by site-directed spin labeling. Biochemistry 2002, 41:6282-6292.

7. Frazier AA, Roller CR, Havelka JJ, Hinderliter A, Cafiso DS: Membrane-bound orientation and position of the synaptotagmin IC2A domain by site-directed spin labeling. Biochemistry 2003, 42:96-105.

8. Kohout SC, Corbalan-Garcia S, Gomez-Fernandez JC, Falke JJ: C2 domain of protein kinase $C$ alpha: Elucidation of the membrane docking surface by site-directed fluorescence and spin labeling. Biochemistry 2003, 42: I 254-1265.

9. Rufener E, Frazier AA, Wieser CM, Hinderliter A, Cafiso DS: Membrane-bound orientation and position of the synaptotagmin C2B domain determined by site-directed spin labeling. Biochemistry 2005, 44: 18-28.

10. Brunecky R, Lee S, Rzepecki PW, Overduin M, Prestwich GD, Kutateladze AG, Kutateladze TG: Investigation of the binding geometry of a peripheral membrane protein. Biochemistry 2005, 44:|6064-|607|.
II. Tatulian SA, Qin S, Pande AH, He X: Positioning membrane proteins by novel protein engineering and biophysical approaches. J Mol Biol 2005, 35 I:939-947.

12. Nina M, Berneche S, Roux B: Anchoring of a monotopic membrane protein: the binding of prostaglandin $\mathrm{H} 2$ synthase- $I$ to the surface of a phospholipid bilayer. Eur Biophys J 2000, 29:439-454.

13. Zhou F, Schulten K: Molecular dynamics study of phospholipase A2 on a membrane surface. Proteins 1996, 25: |2-27.

14. Feig M, Brooks CL: Recent advances in the development and application of implicit solvent models in biomolecule simulations. Curr Opin Struct Biol 2004, 14:217-224.

15. Lazaridis $\mathrm{T}$ : Effective energy function for proteins in lipid membranes. Proteins 2003, 52:176-192.

16. Efremov RG, Nolde DE, Konshina AG, Syrtcev NP, Arseniev AS Peptides and proteins in membranes: what can we learn via computer simulations? Curr Med Chem 2004, I I:242I-2442.

17. Ben-Tal N, Honig B, Miller C, McLaughlin S: Electrostatic binding of proteins to membranes. Theoretical predictions and experimental results with charybdotoxin and phospholipid vesicles. Biophys J 1997, 73:17|7-1727.

18. Murray D, BenTal N, Honig B, McLaughlin S: Electrostatic interaction of myristoylated proteins with membranes: Simple physics, complicated biology. Structure 1997, 5:985-989.

19. Murray D, Honig B: Electrostatic control of the membrane targeting of C2 domains. Mol Cell 2002, 9: I45-I54.

20. Singh SM, Murray D: Molecular modeling of the membrane targeting of phospholipase $\mathbf{C}$ pleckstrin homology domains. Protein Sci 2003, I 2: 1934-1953.

21. Diraviyam K, Stahelin RV, Cho W, Murray D: Computer modeling of the membrane interaction of FYVE domains. I Mol Biol 2003, 328:72I-736.

22. Diraviyam K, Murray D: Computational analysis of the membrane association of group IIA secreted phospholipases A2: a differential role for electrostatics. Biochemistry 2006, 45:2584-2598.

23. Berman HM, Westbrook J, Feng Z, Gilliland G, Bhat TN, Weissig H, Shindyalov IN, Bourne PE: The Protein Data Bank. Nucleic Acids Res 2000, 28:235-242.

24. Lomize MA, Lomize AL, Pogozheva ID, Mosberg HI: OPM: Orientations of proteins in membranes database. Bioinformatics 2006, 22:623-625.

25. Marsh $D$ : Membrane water-penetration profiles from spin labels. Eur Biophys J 2002, 31:559-562.

26. Lomize AL, Pogozheva ID, Lomize MA, Mosberg HI: Positioning of proteins in membranes: A computational approach. Protein Sci 2006, I5:1318-1333.

27. Lomize AL, Pogozheva ID, Mosberg HI: Quantification of helixhelix binding affinities in micelles and lipid bilayers. Protein Sci 2004, 13:2600-2612.

28. Nagle JF, Tristram-Nagle S: Structure of lipid bilayers. Biochim Biophys Acta 2000, I469:159-195.

29. Ulmschneider MB, Sansom MS, Di Nola A: Properties of integral membrane protein structures: derivation of an implicit membrane potential. Proteins 2005, 59:252-265.

30. de Planque MR, Bonev BB, Demmers JA, Greathouse DV, Koeppe RE 2nd, Separovic F, Watts A, Killian JA: Interfacial anchor properties of tryptophan residues in transmembrane peptides can dominate over hydrophobic matching effects in peptide-lipid interactions. Biochemistry 2003, 42:534I-5348.

31. Kachel K, Asuncion-Punzalan E, London E: Anchoring of tryptophan and tyrosine analogs at the hydrocarbon-polar boundary in model membrane vesicles: parallax analysis of fluorescence quenching induced by nitroxide-labeled phospholipids. Biochemistry 1995, 34:15475-15479.

32. Gaede HC, Yau WM, Gawrisch K: Electrostatic contributions to indole-lipid interactions. J Phys Chem B 2005, 109: I 30|4-I 3023.

33. Cafiso DS: Structure and interactions of $C 2$ domains at membrane surfaces. In Protein-Lipid Interactions: From Membrane Domains to Cellular Networks Edited by: Tamm LK. Chichester: John Wiley \& Sons; 2005:403-422.

34. Malmberg NJ, Falke J]: Use of EPR power saturation to analyze the membrane-docking geometries of peripheral proteins: applications to C2 domains. Annu Rev Biophys Biomol Struct 2005, 34:7I-90. 
35. Altenbach C, Greenhalgh DA, Khorana HG, Hubbell WL: A collision gradient method to determine the immersion dept of nitroxides in lipid bilayers: application to spin-labeled mutants of bacteiorhdopsin. Proc Natl Acad Sci USA 1994, 91:1667-167|.

36. Klug CS, Su WY, Feix JB: Mapping of the residues involved in a proposed beta-strand located in the ferric enterobactin receptor FepA using site-directed spin-labeling. Biochemistry 1997, 36: I 3027-I3033.

37. Malkova S, Long F, Stahelin RV, Pingali SV, Murray D, Cho W, Schlossman ML: X-ray reflectivity studies of CPLA2 $\alpha-C 2$ domains adsorbed onto Langmuir monolayers of SOPC. Biophys 」 2005, 89: $|86|-\mid 873$

38. Karathanassis D, Stahelin RV, Bravo J, Perisic O, Pacold CM, Cho W, Williams RL: Binding of the PX domain of p47(phox) to phosphatidylinositol 3,4-bisphosphate and phosphatidic acid is masked by an intramolecular interaction. EMBO J 2002, 2I:5057-5068

39. Stahelin RV, Burian A, Bruzik KS, Murray D, Cho W: Membrane binding mechanisms of the PX domains of NADPH oxidase p40phox and p47phox. J Biol Chem 2003, 278: I4469-I4479.

40. Kutateladze T, Overduin M: Structural mechanism of endosome docking by the FYVE domain. Science 200I, 29I:I793-1796.

4I. Jain MK, Berg OG: Coupling of the i-face and the active site of phospholipase A2 for interfacial activation. Curr Opin Chem Biol 2006, 10:473-479.

42. Lin Y, Nielsen R, Murray D, Hubbell WL, Mailer C, Robinson BH, Gelb MH: Docking phospholipase A2 on membranes using electrostatic potential-modulated spin relaxation magnetic resonance. Science 1998, 279:1925-1929.

43. Canaan S, Nielsen R, Ghomashchi F, Robinson BH, Gelb MH: Unusual mode of binding of human group IIA secreted phospholipase $\mathrm{A} 2$ to anionic interfaces as studied by continuous wave and time domain electron paramagnetic resonance spectroscopy. J Biol Chem 2002, 277:30984-30990.

44. Bak M, Bywater RP, Hohwy M, Thomsen JK, Adelhorst K, Jakobsen $\mathrm{HJ}$, Sorensen OW, Nielsen NC: Conformation of alamethicin in oriented phospholipid bilayers determined by (I5) N solidstate nuclear magnetic resonance. Biophys J 200I, 8I:1684-1698.

45. Barranger-Mathys $M$, Cafiso DS: Membrane structure of voltagegated channel forming peptides by site-directed spin-labeling. Biochemistry 1996, 35:498-505.

46. Bechinger B, Skladnev DA, Ogrel A, Li X, Rogozhkina EV, Ovchinnikova TV, ONeil JD, Raap J: I $5 \mathbf{N}$ and 3 I P solid-state NMR investigations on the orientation of zervamicin II and alamethicin in phosphatidylcholine membranes. Biochemistry 200I, 40:9428-37.

47. Kropacheva TN, Salnikov ES, Nguyen HH, Reissmann S, Yakimenko ZA, Tagaev AA, Ovchinnikova TV, Raap J: Membrane association and activity of 15/16-membered peptide antibiotics: zervamicin IIB, ampullosporin A and antiamoebin I. Biochim Biophys Acta 2005, I7 I5:6-18.

48. Storch J, Thumser AE: The fatty acid transport function of fatty acid-binding proteins. Biochim Biophys Acta 2000, I 486:28-44.

49. Yamada T, Komoto J, Watanabe K, Ohmiya Y, Takusagawa F: Crystal structure and possible catalytic mechanism of microsomal prostaglandin E synthase type 2 (mPGES-2). J Mol Biol 2005, 348: I|63-II76.

50. Kessel A, Ben-Tal N: Free energy determinants of peptide association with lipid bilayers. Current Topics in Membranes 2002, 52:205-253

51. Mclntosh TJ, Vidal A, Simon SA: The energetics of peptide-lipid interactions: modulation by interfacial dipoles and cholesterol. Current Topics in Membranes 2002, 52:309-338.

52. Booth PJ: Sane in the membrane: designing systems to modulate membrane proteins. Curr Opin Struct Biol 2005, 15:435-440.

53. Mclntosh TJ, Simon SA: Roles of bilayer material properties in function and distribution of membrane proteins. Annu Rev Biophys Biomol Struct 2006, 35:177-198.

54. Scholtz JM, Baldwin RL: The mechanism of alpha-helix formation by peptides. Annu Rev Biophys Biomol Struct 1992, 2 1:95-1 I8.

55. Lomize AL, Mosberg HI: Thermodynamic model of secondary structure for alpha-helical peptides and proteins. Biopolymers 1997, 42:239-269.
56. Pan YH, Yu BZ, Singer AG, Ghomashchi F, Lambeau G, Gelb MH, Jain $M K$, Bahnson BJ: Crystal structure of human group $X$ secreted phospholipase A2. Electrostatically neutral interfacial surface targets zwitterionic membranes. J Biol Chem 2002, 277:29086-29093.

57. Bezzine S, Bollinger JG, Singer AG, Veatch SL, Keller SL, Gelb MH: On the binding preference of human groups IIA and $X$ phospholipases A2 for membranes with anionic phospholipids. J Biol Chem 2002, 277:48523-48534.

58. Allende D, Vidal A, Simon SA, Mclntosh TJ: Bilayer interfacial properties modulate the binding of amphipathic peptides. Chem Phys Lipids 2003, I 22:65-76.

59. Andreeva A, Howorth D, Brenner SE, Hubbard TJ, Chothia C, Murzin $A G$ : SCOP database in 2004: refinements integrate structure and sequence family data. Nucleic Acids Res 2004, 32:D226-D229.

60. Bracey MH, Cravatt BF, Stevens RC, Cravatt BF: Structural commonalities among integral membrane enzymes. FEBS Lett 2004, 567:159-165.

61. Craig L, Volkmann N, Arvai AS, Pique ME, Yeager M, Egelman EH, Tainer JA: Type IV pilus structure by cryo-electron microscopy and crystallography: implications for pilus assembly and functions. Mol Cell 2006, 23:65I-662

62. Bhardwaj N, Stahelin RV, Langlois RE, Cho W, Lu H: Structural bioinformatics prediction of membrane-binding proteins. J Mol Biol 2006, 359:486-495.

63. Tusnady GE, Dosztanyi Z, Simon I: Transmembrane proteins in the Protein Data Bank: identification and classification. Bioinformatics 2004, 20:2964-2972.

64. Raman P, Cherezov V, Caffrey M: The Membrane Protein Data Bank. Cell Mol Life Sci 2006, 63:36-5I.

65. Membrane proteins of known 3D structure [http://blanco.bio mol.uci.edu/Membrane Proteins xtal.html]

66. Ducarme P, Rahman M, Brasseur R: IMPALA : A simple restraint field to simulate the biological membrane in molecular structure studies. Proteins 1998, 30:357-371.

67. Seelig J: Thermodynamics of lipid-peptide interactions. Biochim Biophys Acta 2004, 1666:40-50.

68. Killian JA: Hydrophobic mismatch between proteins and lipids in membranes. Biochim Biophys Acta 1998, 1376:40I-4I5.

69. Hanakam F, Gerisch G, Lotz S, Alt T, Seelig A: Binding of hisactophilin I and II to lipid membranes is controlled by a pH. dependent myristoyl-histidine switch. Biochemistry 1996, 35: I 1036-I I044.

70. Zhang W, Crocker E, McLaughlin S, Smith SO: Binding of peptides with basic and aromatic residues to bilayer membranes: phenylalanine in the myristoylated alanine-rich $C$ kinase substrate effector domain penetrates into the hydrophobic core of the bilayer. J Biol Chem 2003, 278:2 I459-2/466.

71. Marcotte I, Dufourc EJ, Ouellet M, Auger M: Interaction of the neuropeptide met-enkephalin with zwitterionic and negatively charged bicelles as viewed by $3 \mathrm{IP}$ and $2 \mathrm{H}$ solid-state NMR. Biophys / 2003, 85:328-339.

72. Ellena JF, Moulthrop J, Wu J, Rauch M, Jaysinghne S, Castle JD, Cafiso DS: Membrane position of a basic aromatic peptide that sequesters phosphatidylinositol 4,5 bisphosphate determined by site-directed spin labeling and high-resolution NMR. Biophys J 2004, 87:322I-3233.

73. Darkes MJM, Davies SMA, Bradshaw JP: Interaction of tachykinins with phospholipid membranes: A neutron diffraction study. Physica 1997, B24 I: I 144- I I47.

74. Hristova K, Wimley WC, Mishra VK, Anantharamiah GM, Segrest JP, White SH: An amphipathic $\alpha$-helix at a membrane interface: A structural study using a novel $X$-ray diffraction method. J Mol Biol 1999, 290:99-117.

75. Yau W-M, Wimley WC, Gawrisch K, White SH: The preference of tryptophan for membrane interfaces. Biochemistry 1998, 37:147|3-147|8.

76. Sankaram MB, Marsh D: Protein-lipid interactions with peripheral membrane proteins. In Protein-lipid interactions Edited by: Watts A. Elsevier; 1993:127-162.

77. Stahelin RV, Long F, Peter BJ, Murray D, De Camilli P, McMahon HT, Cho W: Contrasting membrane interaction mechanisms of API $80 \mathrm{~N}$-terminal homology (ANTH) and epsin N-terminal homology (ENTH) domains. J Biol Chem 2003, 278:28993-28999. 
78. Scholtz JM, Qian H, Robbins VH, Baldwin RL: The energetics of ion-pair and hydrogen-bonding interactions in a helical peptide. Biochemistry 1993, 32:9668-9676.

79. Richards FM: Areas, volumes, packing, and protein structure. Annu Rev Biophys Bioeng 1977, 6:151-176.

80. Chothia C: Structural invariants in protein folding. Nature 1975, 254:304-308

81. Marsh D: Polarity and permeation profiles in lipid membranes. Proc Natl Acad Sci USA 200I, 98:7777-7782.

82. Henrick K, Thornton JM: PQS: a protein quaternary structure file server. Trends Biochem Sci 1998, 23:358-36I.

83. Krissinel E, Henrick K: Secondary-structure matching (SSM), a new tool for fast protein structure alignment in three dimensions. Acta Crystallogr D Biol Crystallogr 2004, 60:2256-2268.

84. Bittova L, Sumandea M, Cho W: A structure-function study of the C2 domain of cytosolic phospholipase A2. Identification of essential calcium ligands and hydrophobic membrane binding residues. J Biol Chem 1999, 274:9665-9672.

85. Malmberg NJ, Van Buskirk DR, Falke JJ: Membrane-docking loops of the CPLA2 C2 domain: Detailed structural analysis of the protein-membrane interface via site-directed spin-labeling. Biochemistry 2003, 42: I 3227- I 3240.

86. Gerber SH, Rizo J, Sudhof TC: Role of electrostatic and hydrophobic interactions in $\mathbf{C a}(2+)$-dependent phospholipid binding by the $\mathbf{C}(2) A-d o m a i n$ from synaptotagmin I. Diabetes 2002, 5 I (SuppI I):SI 2-SI8.

87. Corbalan-Garcia S, Sanchez-Carrillo S, Garcia-Garcia J, Gomez-Fernandez JC: Characterization of the membrane binding mode of the C2 domain of PKC epsilon. Biochemistry 2003, 42: I| 66 I- || 668 .

88. Stahelin RV, Long F, Diraviyam K, Bruzik KS, Murray D, Cho W: Phosphatidylinositol 3-phosphate induces the membrane penetration of the FYVE domains of Vps27p and Hrs. J Biol Chem 2002, 277:26379-26388.

89. Wang QJ, Fang TW, Nacro K, Marquez VE, Wang S, Blumberg PM: Role of hydrophobic residues in the $\mathrm{Clb}$ domain of protein kinase $\mathbf{C}$ delta on ligand and phospholipid interactions. J Biol Chem 2001, 276:19580-19587.

90. Kim SW, Quinn-Allen MA, Camp JT, Macedo-Ribeiro S, Fuentes-Prior $\mathrm{P}$, Bode $\mathrm{W}$, Kane $\mathrm{WH}$ : Identification of functionally important amino acid residues within the C2-domain of human factor V using alanine-scanning mutagenesis. Biochemistry 2000, 39:1951-1958.

91. Peng W, Quinn-Allen MA, Kane WH: Mutation of hydrophobic residues in the factor $\mathrm{Va} \mathrm{Cl}$ and $\mathrm{C2}$ domains blocks membrane-dependent prothrombin activation. J Thromb Haemost 2005, 3:35I-354.

92. Gilbert GE, Kaufman RJ, Arena AA, Miao H, Pipe SW: Four hydrophobic amino acids of the factor VIII C2 domain are constituents of both the membrane-binding and von Willebrand factor-binding motifs. I Biol Chem 2002, 277:6374-638I.

93. Campos B, Mo YD, Mealy TR, Li CW, Swairjo MA, Balch C, Head JF, Retzinger G, Dedman JR, Seaton BA: Mutational and crystallographic analyses of interfacial residues in annexin $V$ suggest direct interactions with phospholipid membrane components. Biochemistry 1998, 37:8004-8010.

94. Isas JM, Langen R, Hubbell WL, Haigler HT: Structure and dynamics of a helical hairpin that mediates calcium-dependent membrane binding of annexin BI2. I Biol Chem 2004, 279:32492-32498.

95. Anderluh G, Razpotnik A, Podlesek Z, Macek P, Separovic F, Norton RS: Interaction of the eukaryotic pore-forming cytolysin equinatoxin II with model membranes: I9F NMR studies. J Mol Biol 2005, 347:27-39.

96. Spencer AG, Thuresson E, Otto JC, Song I, Smith T, DeWitt DL, Garavito RM, Smith WL: The membrane binding domains of prostaglandin endoperoxide $H$ synthases $I$ and 2 . Peptide mapping and mutational analysis. I Biol Chem 1999, 274:32936-32942

97. Shenkarev ZO, Nadezhdin KD, Sobol VA, Sobol AG, Skjeldal L Arseniev AS: Conformation and mode of membrane interaction in cyclotides. FEBS J 2006, 273:2658-2672.

98. Stahelin RV, Cho W: Differential roles of ionic, aliphatic, and aromatic residues in membrane-protein interactions: a surface plasmon resonance study on phospholipases A2. Biochemistry 200I, 40:4672-4678.
99. Lathrop B, Gadd M, Biltonen RL, Rule GS: Changes in Ca2+ affinity upon activation of Agkistrodon piscivorus piscivorus phospholipase A2. Biochemistry 200I, 40:3264-3272.

100. Wijewickrama GT, Albanese A, Kim YJ, Oh YS, Murray PS, Takayanagi R, Tobe T, Masuda S, Murakami M, Kudo I, Ucker DS, Murray D, Cho W: Unique membrane interaction mode of group IIF phospholipase A2. J Biol Chem 2006, 28 I:3274|-32754.

I0I. Feng J, Bradley WD, Roberts MF: Optimizing the interfacial binding and activity of a bacterial phosphatidylinositol-specific phospholipase C. J Biol Chem 2003, 278:2465 I-24657.

102. Jepson M, Bullifent HL, Crane D, Flores-Diaz M, Alape-Giron A, Jayasekeera $\mathrm{P}$, Lingard $\mathrm{B}$, Moss $\mathrm{D}$, Titball RW: Tyrosine $33 \mathrm{I}$ and phenylalanine 334 in Clostridium perfringens alpha-toxin are essential for cytotoxic activity. FEBS Lett 200I, 495: I72-177.

103. Walther $M$, Wiener $\mathrm{R}$, Kuhn $\mathrm{H}$ : Investigations into calciumdependent membrane association of I 5-lipoxygenase-I. J Biol Chem 2004, 279:3717-3725.

104. Oldham ML, Brash AR, Newcomer ME: Insights from the X-ray crystal structure of coral 8R-lipoxygenase: calcium activation via a C2-like domain and a structural basis of product chirality. J Biol Chem 2005, 280:39545-39552.

105. Chen X, Wolfgang DE, Sampson NS: Use of the parallax-quench method to determine the position of the active-site loop of cholesterol oxidase in lipid bilayers. Biochemistry 2000, 39: 13383-13389.

106. Kim YT, Muramatsu T, Takahashi K: Identification of Trp300 as an important residue for Escherichia coli leader peptidase activity. Eur J Biochem 1995, 234:358-362.

107. Cheetham JJ, Hilfiker S, Benfenati F, Weber T, Greengard P, Czernik AJ: Identification of synapsin I peptides that insert into lipid membranes. Biochem J 200I, 354(Pt I):57-66.

108. Jao CC, Der-Sarkissian A, Chen J, Langen R: Structure of membrane-bound alpha-synuclein studied by site-directed spin labeling. Proc Natl Acad Sci USA 2004, 1 0 1:8331-8336.

109. Sekino-Suzuki N, Nakamura M, Mitsui KI, Ohno-Iwashita Y: Contribution of individual tryptophan residues to the structure and activity of theta-toxin (perfringolysin $\mathbf{0}$ ), a cholesterol-binding cytolysin. Eur J Biochem 1996, 241:941-947.

I I0. Lakey JH, Ptak M: Fluorescence indicates a calcium-dependent interaction between the lipopeptide antibiotic LY/46032 and phospholipid membranes. Biochemistry 1988, 27:4639-4645.

I II. Nguyen LT, Schibli DJ, Vogel HJ: Structural studies and model membrane interactions of two peptides derived from bovine lactoferricin. J Pept Sci 2005, I I:379-389.

II2. Phillips LR, Milescu M, Li-Smerin Y, Mindell JA, Kim Jl, Swartz KJ: Voltage-sensor activation with a tarantula toxin as cargo. Nature 2005, 436:857-860.

I 13. Thennarasu S, Lee DK, Poon A, Kawulka KE, Vederas JC, Ramamoorthy $A$ : Membrane permeabilization, orientation, and antimicrobial mechanism of subtilosin A. Chem Phys Lipids 2005, |37:38-5I.

I 14. Xu RX, Pawelczyk T, Xia TH, Brown SC: NMR structure of a protein kinase $\mathrm{C}$-gamma phorbol-binding domain and study of protein-lipid micelle interactions. Biochemistry 1997, 36:10709-10717.

115. Hofmann A, Proust J, Dorowski A, Schantz R, Huber R: Annexin 24 from Capsicum annuum. X-ray structure and biochemical characterization. J Biol Chem 2000, 275:8072-8082.

I 16. McCallum CD, Hapak RC, Neuenschwander PF, Morrissey JH, Johnson $\mathrm{AE}$ : The location of the active site of blood coagulation factor VIla above the membrane surface and its reorientation upon association with tissue factor. A fluorescence energy transfer study. J Biol Chem 1996, 27I:28I68-28I75.

I17. Ramakrishnan M, Anbazhagan V, Pratap TV, Marsh D, Swamy MJ: Membrane insertion and lipid-protein interactions of bovine seminal plasma protein PDC-I09 investigated by spin-label electron spin resonance spectroscopy. Biophys J 200I, 81:2215-2225.

I 18. Huang WN, Sue SC, Wang DS, Wu PL, Wu WG: Peripheral binding mode and penetration depth of cobra cardiotoxin on phospholipid membranes as studied by a combined FTIR and computer simulation approach. Biochemistry 2003, 42:7457-7466.

I 19. Batenburg AM, Bougis PE, Rochat H, Verkleij AJ, de Kruijff B: Penetration of a cardiotoxin into cardiolipin model membranes 
and its implications on lipid organization. Biochemistry 1985, 24:7I0I-7IIO

120. Dubovskii PV, Dementieva DV, Bocharov EV, Utkin YN, Arseniev AS Membrane binding motif of the P-type cardiotoxin. I Mol Bio 200I, 305: I37-I49.

12I. Takeuchi K, Takahashi H, Sugai M, Iwai H, Kohno T, Sekimizu K, Natori S, Shimada I: Channel-forming membrane permeabilization by an antibacterial protein, sapecin: determination of membrane-buried and oligomerization surfaces by NMR. Biol Chem 2004, 279:498I-4987.

122. Kostrzewa A, Pali T, Froncisz W, Marsh D: Membrane location of spin-labeled cytochrome $c$ determined by paramagnetic relaxation agents. Biochemistry 2000, 39:6066-6074

123. Pinheiro TJ, Watts A: Lipid specificity in the interaction of cytochrome $c$ with anionic phospholipid bilayers revealed by solid-state 3 IP NMR. Biochemistry 1994, 33:245 I-2458.

124. Mutucumarana VP, Duffy EJ, Lollar P, Johnson AE: The active site of factor IXa is located far above the membrane surface and its conformation is altered upon association with factor VIIla. A fluorescence study. I Biol Chem 1992, 267:I7012-I702I.

125. Yegneswaran S, Wood GM, Esmon CT, Johnson AE: Protein S alters the active site location of activated protein $C$ above the membrane surface. A fluorescence resonance energy transfer study of topography. J Biol Chem 1997, 272:250|3-2502I

126. Matsuzaki K, Murase O, Tokuda H, Funakoshi S, Fujii N, Miyajima K: Orientational and aggregational states of magainin 2 in phospholipid bilayers. Biochemistry 1994, 33:3342-3349.

127. Marassi FM, Ma C, Gesell J], Opella SJ: Three-dimensional solidstate NMR spectroscopy is essential for resolution of resonances from in-plane residues in uniformly (15)N-labeled helical membrane proteins in oriented lipid bilayers. J Magn Reson 2000, 144:156-161.

128. Bonev BB, Chan WC, Bycroft BW, Roberts GC, Watts A: Interaction of the lantibiotic nisin with mixed lipid bilayers: a 3 IP and 2H NMR study. Biochemistry 2000, 39: I | 425-I I 433 .

129. Thomas L, Scheidt HA, Bettio A, Huster D, Beck-Sickinger AG, Arnold K, Zschornig O: Membrane interaction of neuropeptide Y detected by EPR and NMR spectroscopy. Biochim Biophys Acta 2005, 17| 4:103-113.

130. Hsu ST, Breukink E, Bierbaum G, Sahl HG, de Kruijff B, Kaptein R, van Nuland NA, Bonvin AM: NMR study of mersacidin and lipid II interaction in dodecylphosphocholine micelles. Conformational changes are a key to antimicrobial activity. J Biol Chem 2003, 278: $|3| 10-13 \mid 17$

13I. Tesmer VM, Kawano T, Shankaranarayanan A, Kozasa T, Tesmer J]: Snapshot of activated $\mathbf{G}$ proteins at the membrane: the $\mathbf{G} \alpha \mathbf{q}$ GRK2-G $\beta \gamma$ complex. Science 2005, 3 I 0: 1686-1690.

132. Wah DA, Fernandez-Tornero C, Sanz L, Romero A, Calvete JJ: Sperm coating mechanism from the I.8 A crystal structure of PDC-109-phosphorylcholine complex. Structure 2002 10:505-5।4.

133. Begley MJ, Taylor GS, Brock MA, Ghosh P, Woods VL, Dixon JE: Molecular basis for substrate recognition by MTMR2, a myotubularin family phosphoinositide phosphatase. Proc Natl Acad Sci USA 2006, 103:927-932.

134. Bracey MH, Hanson MA, Masuda KR, Stevens RC, Cravatt BF: Structural adaptations in a membrane enzyme that terminates endocannabinoid signaling. Science 2002, 298: 1793-1796.

135. Paetzel M, Dalbey RE, Strynadka NC: Crystal structure of a bacterial signal peptidase in complex with a beta-lactam inhibitor. Nature 1998, 396: I86-190.

136. Thoma R, Schulz-Gasch T, D'Arcy B, Benz J, Aebi J, Dehmlow H, Hennig $M$, Stihle M, Ruf $A$ : Insight into steroid scaffold formation from the structure of human oxidosqualene cyclase. Nature 2004, 432: I 18-122.

137. Ma J, Yoshimura M, Yamashita E, Nakagawa A, Ito A, Tsukihara T: Structure of rat monoamine oxidase $A$ and its specific recognitions for substrates and inhibitors. J Mol Biol 2004, 338: $103-114$.

138. Rufer AC, Thoma R, Benz J, Stihle M, Gsell B, De Roo E, Banner DW, Mueller F, Chomienne $O$, Hennig M: The crystal structure of carnitine palmitoyltransferase $\mathbf{2}$ and implications for diabetes treatment. Structure 2006, 14:7/3-723.
139. Modis Y, Ogata S, Clements D, Harrison SC: Structure of the dengue virus envelope protein after membrane fusion. Nature 2004, 427:313-319.

140. Wu CK, Dailey HA, Rose JP, Burden A, Sellers VM, Wang BC: The 2.0 A structure of human ferrochelatase, the terminal enzyme of heme biosynthesis. Nat Struct Biol 200I, 8: 156-I60.

14I. Openshaw AE, Race PR, Monzo HJ, Vazquez-Boland JA, Banfield MJ: Crystal structure of SmcL, a bacterial neutral sphingomyelinase C from Listeria. J Biol Chem 2005, 280:350 I I-350I7.

142. Clark GC, Briggs DC, Karasawa T, Wang X, Cole AR, Maegawa T, Jayasekera PN, Naylor CE, Miller J, Moss DS, Nakamura S, Basak AK, Titball RW: Clostridium absonum alpha-toxin new insights into clostridial phospholipase $\mathbf{C}$ substrate binding and specificity. J Mol Biol 2003, 333:759-769.

143. Akiba T, Nishio M, Matsui I, Harata K: X-ray structure of a membrane-bound beta-glycosidase from the hyperthermophilic archaeon Pyrococcus horikoshii. Proteins 2004, 57:422-43I.

144. Zhang J, Osslund TD, Plant MH, Clogston CL, Nybo RE, Xiong F, Delaney JM, Jordan SR: Crystal structure of murine II betahydroxysteroid dehydrogenase I: an important therapeutic target for diabetes. Biochemistry 2005, 44:6948-6957.

145. Kloer DP, Ruch S, Al-Babili S, Beyer P, Schulz GE: The structure of a retinal-forming carotenoid oxygenase. Science 2005, 308:267-269.

146. Meier R, Tomizaki T, Schulze-Briese C, Baumann U, Stocker A: The molecular basis of vitamin $E$ retention: structure of human $\alpha$-tocopherol transfer protein. J Mol Biol 2003, 331:725-734.

147. Phillips SE, Vincent P, Rizzieri KE, Schaaf G, Bankaitis VA, Gaucher EA: The diverse biological functions of phosphatidylinositol transfer proteins in eukaryotes. Crit Rev Biochem Mol Biol 2006, 4I:2I-49.

148. Wright CS, Zhao Q, Rastinejad F: Structural analysis of lipid complexes of GM2-activator protein. J Mol Biol 2003, 331:95I-964.

149. Im YJ, Raychaudhuri S, Prinz WA, Hurley JH: Structural mechanism for sterol sensing and transport by OSBP-related proteins. Nature 2005, 437:154-I58.

150. Coulon A, Mosbah A, Lopez A, Sautereau AM, Schaller G, Urech K, Rouge $\mathrm{P}$, Darbon $\mathrm{H}$ : Comparative membrane interaction study of viscotoxins A3, A2 and B from mistletoe (Viscum album) and connections with their structures. Biochem J 2003, 374:7I-78.

15I. Ahn KW, Sampson NS: Cholesterol oxidase senses subtle changes in lipid bilayer structure. Biochemistry 2004, 43:827-836.

152. Jung HJ, Lee JY, Kim SH, Eu YJ, Shin SY, Milescu M, Swartz KJ, Kim Jl: Solution structure and lipid membrane partitioning of VSTXI, an inhibitor of the KvAP potassium channel. Biochemistry 2005, 44:6015-6023.

153. Kamimori H, Hall K, Craik DJ, Aguilar MI: Studies on the membrane interactions of the cyclotides kalata $\mathrm{BI}$ and kalata B6 on model membrane systems by surface plasmon resonance. Anal Biochem 2005, 337:149-153.

154. Bollinger JG, Diraviyam K, Ghomashchi F, Murray D, Gelb MH: Interfacial binding of bee venom secreted phospholipase A2 to membranes occurs predominantly by a nonelectrostatic mechanism. Biochemistry 2004, 43: I3293-13304.

155. Beschiaschvili G, Seelig J: Peptide binding to lipid bilayers. Nonclassical hydrophobic effect and membrane-induced pK shifts. Biochemistry 1992, 31:10044-10053.

156. Tsujita T, Brockman HL: Regulation of carboxylester lipase adsorption to surfaces. I. Chemical specificity. Biochemistry 1987, 26:8423-8429.

157. Abraham T, Lewis RN, Hodges RS, McElhaney RN: Isothermal titration calorimetry studies of the binding of the antimicrobial peptide gramicidin $S$ to phospholipid bilayer membranes. Biochemistry 2005, 44: I I 279- I I 285.

158. Stahelin RV, Cho W: Roles of calcium ions in the membrane binding of C2 domains. Biochem J 200I, 359:679-685.

159. Ananthanarayanan B, Das S, Rhee SG, Murray D, Cho W: Membrane targeting of $C 2$ domains of phospholipase $C-\delta$ isoforms. J Biol Chem 2002, 277:3568-3575.

160. Nalefski EA, Wisner MA, Chen JZ, Sprang SR, Fukuda M, Mikoshiba $\mathrm{K}$, Falke J]: C2 domains from different $\mathrm{Ca2}+$ signaling pathways display functional and mechanistic diversity. Biochemistry 200I, 40:3089-3100. 
161. Stahelin RV, Rafter JD, Das S, Cho W: The molecular basis of differential subcellular localization of $\mathrm{C2}$ domains of protein kinase C-alpha and group IVa cytosolic phospholipase A2. J Biol Chem 2003, 278: I2452-12460.

162. Das S, Dixon JE, Cho W: Membrane-binding and activation mechanism of PTEN. Proc Natl Acad Sci USA 2003, 100:749I-7496.

163. Koppaka V, Lentz BR: Binding of bovine factor Va to phosphatidylcholine membranes. Biophys J 1996, 70:2930-2937.

164. Blatner NR, Stahelin RV, Diraviyam K, Hawkins PT, Hong W, Murray $\mathrm{D}$, Cho W: The molecular basis of the differential subcellular localization of FYVE domains. J Biol Chem 2004, 279:53818-53827.

165. Wang T, Pentyala S, Rebecchi MJ, Scarlata S: Differential association of the pleckstrin homology domains of phospholipases C- $\beta$ I, C- $\beta 2$, and $\mathbf{C}-\delta$ I with lipid bilayers and the beta gamma subunits of heterotrimeric G proteins. Biochemistry 1999, 38:1517-1524.

166. Hong Q, Gutierrez-Aguirre I, Barlic A, Malovrh P, Kristan K, Podlesek Z, Macek P, Turk D, Gonzalez-Manas JM, Lakey JH, Anderluh G: Two-step membrane binding by Equinatoxin II, a pore-forming toxin from the sea anemone, involves an exposed aromatic cluster and a flexible helix. J Biol Chem 2002, 277:41916-41924.

167. Rietveld A, Sijens P, Verkleij AJ, Kruijff BD: Interaction of cytochrome $c$ and its precursor apocytochrome $c$ with various phospholipids. EMBO J 1983, 2:907-9/3.

168. Wieprecht T, Beyermann M, Seelig J: Binding of antibacterial magainin peptides to electrically neutral membranes: thermodynamics and structure. Biochemistry 1999, 38: 10377-10387.

169. Lewis JR, Cafiso DS: Correlation between the free energy of a channel-forming voltage-gated peptide and the spontaneous curvature of bilayer lipids. Biochemistry 1999, 38:5932-5938.

170. Peng W, Quinn-Allen MA, Kim SW, Alexander KA, Kane WH: Trp2063 and Trp2064 in the factor Va C2 domain are required for high-affinity binding to phospholipid membranes but not for assembly of the prothrombinase complex. Biochemistry 2004, 43:4385-4393.

171. Tatulian SA: Quantitative characterization of membrane binding of peripheral proteins by spin-label EPR spectroscopy. J Phys Chem 2002, B I 06:8870-8877.

\section{Publish with Bio Med Central and every scientist can read your work free of charge}

"BioMed Central will be the most significant development for disseminating the results of biomedical research in our lifetime. "

Sir Paul Nurse, Cancer Research UK

Your research papers will be:

- available free of charge to the entire biomedical community

- peer reviewed and published immediately upon acceptance

- cited in PubMed and archived on PubMed Central

- yours - you keep the copyright

Submit your manuscript here:

http://www.biomedcentral.com/info/publishing_adv.asp
BioMedcentral 